Research Article

\title{
Evaluation and Error Correction of the ECMWF Subseasonal Precipitation Forecast over Eastern China during Summer
}

\author{
Huanran He $\mathbb{D},{ }^{1}$ Suxiang Yao $\mathbb{D},{ }^{1}$ Anning Huang, ${ }^{2}$ and Kejian Gong $\mathbb{D}^{3}$ \\ ${ }^{1}$ Key Laboratory of Meteorological Disaster, Ministry of Education, \\ Joint International Research Laboratory of Climate and Environment Change, \\ Collaborative Innovation Center on Forecast and Evaluation of Meteorological Disasters, \\ Nanjing University of Information Science \& Technology, Nanjing 210044, China \\ ${ }^{2}$ School of Atmospheric Sciences, Nanjing University, Nanjing 210023, China \\ ${ }^{3}$ Meteorological Observatory of Ningxia Civil Aviation ATC, Ningxia 750000, China \\ Correspondence should be addressed to Suxiang Yao; yaosx@nuist.edu.cn
}

Received 18 April 2019; Revised 20 January 2020; Accepted 3 February 2020; Published 17 March 2020

Academic Editor: Helena A. Flocas

Copyright (C) 2020 Huanran He et al. This is an open access article distributed under the Creative Commons Attribution License, which permits unrestricted use, distribution, and reproduction in any medium, provided the original work is properly cited.

Subseasonal-to-seasonal (S2S) prediction is a highly regarded skill around the world. To improve the S2S forecast skill, an S2S prediction project and an extensive database have been established. In this study, the European Center for Medium-Range Weather Forecasts (ECMWF) model hindcast, which participates in the S2S prediction project, is systematically assessed by focusing on the hindcast quality for the summer accumulated ten-day precipitation at lead times of 0-30 days during 1995-2014 in eastern China. Additionally, the hindcast error is corrected by utilizing the preceding sea surface temperature (SST). The metrics employed to measure the ECMWF hindcast performance indicate that the ECMWF model performance drops as the lead time increases and exhibits strong interannual differences among the five subregions of eastern China. In addition, the precipitation forecast skill of the ECMWF hindcast is best at approximately 15 days in some areas of Southeast China; after correcting the forecast error, the forecast skill is increased to 30 days. At lead times of 0-30 days, regardless of whether the forecast error is corrected, the root mean square errors are lowest in Northeast China. After correcting the forecast error, the performance of the ECMWF hindcast shows better improvement in depicting the quantity and temporal and spatial variation of precipitation at lead times of 0-30 days in eastern China. The false alarm ratio (FAR), probability of detection (POD), and equitable threat score (ETS) reveal that the ECMWF model has a preferable performance at forecasting accumulated ten-day precipitation rates of approximately $20 \sim 50 \mathrm{~mm}$ and indicates an improved hindcast quality after the forecast error correction. In short, adopting the preceding SST to correct the summer subseasonal precipitation of the ECMWF hindcast is preferable.

\section{Introduction}

Traditional weather forecasting is limited to 2 weeks and is mainly influenced by atmospheric initial conditions [1-3]. Seasonal climate predictability is substantially affected by the underlying boundary forcing, such as sea surface temperature (SST) and land surface anomalies [4-6]. Subseasonal forecasting, which fills a gap between traditional mediumterm weather and seasonal climate forecasting, is significantly influenced by both atmospheric initial conditions and boundary forcing $[7,8]$. Compared to weather and seasonal climate forecasting, subseasonal forecasting is considered a "predictability desert" [9] and is at a relatively early stage of development [8]. Recently, some studies have shown the potential sources of subseasonal predictability, such as the state of El Nino-Southern Oscillation (ENSO) [10], the MaddenJulian Oscillation (MJO) [11-13], initial soil moisture conditions [14, 15], snow cover [16] and sea-ice conditions [17], stratosphere-troposphere interactions $[18,19]$, and tropicalextratropical teleconnections [20, 21].

Under the background of global warming, extreme weather events, especially droughts and floods in summer, are relatively frequent and continuous over China. These extreme weather events not only directly affect the growth 
and yield of crops but also pose threats to people's lives and the national economy. Skillful subseasonal forecasting is of great significance for reducing the losses caused by meteorological disasters. Therefore, whether the goal is to fill the "predictability gap" or to achieve disaster prevention and mitigation, providing accurate forecasts on a subseasonal timescale is extremely vital. Dynamic forecasting models have been used in subseasonal forecasting, and multiple global ensemble prediction systems have been assessed. These prediction systems presented a higher precipitation forecast skill in the first week than in the following three weeks, and the skill dropped with an increase in the lead time $[13,22,23]$. Additionally, many dynamic forecasting models derived useful forecast skills of the MJO at lead times of 2-3 weeks and beyond [24-27]. The statistical forecast method is another popular tool for subseasonal forecasting. A spatial-temporal projection model was adopted to forecast 10-30 days of low-frequency precipitation, and the results showed that the forecast skill is approximately $20-25$ days in most of China $[28,29]$. In recent years, to improve the subseasonal-to-seasonal (S2S) forecast skill and understand this timescale, the World Weather Research Program (WWRP) and World Climate Research Program (WCRP) established the S2S prediction research project $[9,30]$. This project aimed to establish an extensive database, which currently archives near-real-time forecasts and hindcasts (reforecasts) up to 60 days from one research institute and ten operational centers [8]. Currently, the S2S database has been adopted for research on different subseasonal issues. The forecast skill of the boreal summer intraseasonal oscillation (BSISO) was assessed using the S2S database, and the results showed that the forecast skill of the BSISO reaches up to 10-24.5 days when using the ensemble mean and that the performance of the European Center for Medium-Range Weather Forecasts (ECMWF) model is the best [31]. Additionally, the hindcast quality of the subseasonal global precipitation from 11 S2S models was evaluated, which revealed that the forecast performance of an S2S model is the highest in the first week and that the ECMWF hindcast boasts the best forecast capability [32]. Liang and Lin [10] analyzed the forecast skills of the 2-meter air temperature $(\mathrm{T} 2 \mathrm{~m}), 500 \mathrm{hPa}$ geopotential height (Z500), and precipitation for the Environment and Climate Change Canada (ECCC) model. They showed that the forecast skills of T2m and Z500 reach up to 4 weeks (26-32 days), while the forecast skill of precipitation is limited to 5-11 days in summer over East Asia. The capabilities of the ECMWF, National Centers for Environmental Prediction (NCEP), and China Meteorological Administration (CMA) models at forecasting summer subseasonal precipitation in the North American (NAM), West African (WAM), and Asian (AM) summer monsoon regions were also explored [33]. Moreover, the hindcasts of $11 \mathrm{~S} 2 \mathrm{~S}$ models were assessed to investigate the influence of the $\mathrm{MJO}$ on the forecast skill of the winter T2M over China [34]. According to previous studies, the 11 S2S models are considered the main tools for providing forecasts on the S2S timescale. However, the forecast capability of the ECMWF model was found to be superior among the $11 \mathrm{~S} 2 \mathrm{~S}$ models regarding precipitation. In China, extreme precipitation events are frequent and continuous. Therefore, investigating the performance of the ECMWF model at forecasting summer subseasonal precipitation in China and correcting the forecast error to improve the forecast performance therein is very meaningful.

As one of the vital forcing sources of the atmospheric circulation, the SST has a strong memory, and its persistence plays an important role in climate change. For many years, the relationship between the preceding SST of the global ocean and summer precipitation in China has been widely studied. Fu et al. [35] indicated a high correlation between the preceding SST, especially from March to May in the Pacific Ocean, and summer precipitation in the Huaihe River Basin. Regarding the forcing of the preceding SST, SST anomalies in the midlatitude North Atlantic and subtropical southeastern Pacific in spring were found to strongly influence summer precipitation in Northeast China [36, 37]. Deng et al. [38] revealed that precipitation in the first annual rainy season from April to June in South China is affected by the SST ahead of two months in the South China Sea, the Western Pacific Ocean, and the Arabian Sea. In addition, studies have shown that the SST forcing over the Indian Ocean, Pacific Ocean, and Atlantic Ocean in spring can cause summer precipitation anomalies in China [39, 40]. Wang and Zhang [40] used the distribution of specific preceding SSTs globally as a signal factor to predict summer precipitation in China, and the use of this factor effectively improved the accuracy of the prediction. Hence, the preceding SST anomaly forcing is a significant indicator of the precipitation forecasting in China. In this paper, based on the relationship between the preceding SST and summer subseasonal precipitation in China, the forecast error of the ECMWF S2S model will be corrected to enhance the performance of the model.

Section 2 presents the data and methods. In Section 3, the performance of the ECMWF model at forecasting summer subseasonal precipitation is assessed, and the forecast error of the ECMWF model is corrected using the preceding SST during 1995-2014 in eastern China. The main summary and discussion are shown in Section 4.

\section{Data and Methods}

2.1. Data. In this study, the hindcast performance of the ECMWF S2S model at forecasting summer subseasonal precipitation in eastern China is evaluated, and the forecast error is corrected. The data used for the model evaluation and error correction are as follows:

(1) Hindcast data at a spatial resolution of $1.5^{\circ} \times 1.5^{\circ}$ from the ECMWF, the Japan Meteorological Agency (JMA), and the CMA provided by the S2S database. This database is archived at ECMWF (http://apps. ecmwf.int/datasets/data/s2s/) and CMA (http://s2s. cma.cn/) [8]. Three hindcast models provide precipitation estimates, and Table 1 shows their main features. Because this research mainly studies summer precipitation, the hindcast covers the period from May to August. The ECMWF model runs for 46 
TABLE 1: The main hindcast (reforecast) feature of ECMWF, JMA, and CMA S2S models [8].

\begin{tabular}{|c|c|c|c|c|c|c|c|c|}
\hline Model & Time range & Resolution & Reforecasts (Rfc) & Rfc frequency & Rfc period & Rfc size & Ocean coupled & Sea-ice coupled \\
\hline ECMWF & Days $0-46$ & Tco639/Tco319, L91 & On the fly & 2/week & Past 20 years & 11 & Yes & No \\
\hline JMA & Days 0-33 & TL479/TL319, L100 & Fixed & $3 /$ month & $1981-2010$ & 5 & No & No \\
\hline CMA & Days 0-60 & T106, L40 & Fixed & Daily & 1994-2014 & 4 & Yes & Yes \\
\hline
\end{tabular}

days starting from May 14th over the period of 1995-2014; the JMA model runs for 33 days starting from May 10th over the period of 1981-2010; and the CMA model runs for 60 days starting from May 14th over the period of 1994-2014. The common years of all three hindcasts are 1995-2010. For comparison purposes, the CMA hindcast takes only the forecast time of the ECMWF hindcast.

(2) China's Ground Precipitation $0.5^{\circ} \times 0.5^{\circ}$ Gridded Dataset (V2.0) supplied by the National Meteorological Information Center of the China Meteorological Administration covering the time period from May 1995 to September 2014. To unify the spatial resolution of the precipitation and observation data from the three hindcast experiments, a $1.5^{\circ}$ latitude and longitude grid is interpolated to a $0.5^{\circ}$ latitude and longitude grid.

(3) Monthly sea surface temperature data (HadISST) [41] with a spatial resolution of $1^{\circ} \times 1^{\circ}$ covering the period from April 1995 to June 2014 from the Met Office Hadley Center. Due to the limitation on atmospheric predictability, subseasonal predictions are not as accurate (to the day or the hour) as weather forecasts. Combined with previous research achievements in subseasonal forecasting, the hindcasts of the S2S models are processed as accumulated ten-day precipitation forecasts.

2.2. Methods. Many statistical measures, such as the Pearson correlation coefficient (RR), the anomaly correlation coefficient (ACC), the total error, and the variance ratio, are commonly used in the forecasting business to evaluate the forecast performance of a model. In this paper, six kinds of metrics, namely, the Pearson correlation coefficient, root mean square error (RMSE), standardized RMSE, false alarm ratio (FAR), probability of detection (POD), and equitable threat score (ETS), are utilized to quantitatively evaluate the hindcast experiments' performance. The correlation coefficient is used to evaluate the models' forecast performance by characterizing the consistency of the temporal or spatial variation between the hindcast experiment precipitation and the observed precipitation. In addition, the RMSE is adopted to reveal the forecast performance of the hindcast experiments by calculating the error between the hindcast and observed precipitation. Moreover, for the purpose of eliminating the geographical effect of precipitation over eastern China, the standardized RMSE is adopted. The formulas of the Pearson correlation coefficient, RMSE, and standardized RMSE are given as follows:

$$
R=\frac{\sum_{i=1}^{N}\left(F_{i}-\bar{F}\right)\left(O_{i}-\bar{O}\right)}{\sqrt{\sum_{i=1}^{N}\left(F_{i}-\bar{F}\right)^{2}} \sqrt{\sum_{i=1}^{N}\left(O_{i}-\bar{O}\right)^{2}}}
$$

$$
\mathrm{RMSE}=\sqrt{\frac{1}{N} \sum_{i=1}^{N}\left(F_{i}-O_{i}\right)^{2}},
$$

Standardized RMSE $=\frac{\sqrt{(1 / N) \sum_{i=1}^{N}\left(F_{i}-O_{i}\right)^{2}}}{\bar{O}}$,

where $F(O)$ is the precipitation of the S2S hindcast experiment (observation data), $i$ refers to a temporal or spatial point, and $N$ indicates the number of temporal or spatial points. $\bar{F}(\bar{O})$ expresses the average value of the hindcast (observation) data at $N$ discrete points. The temporal correlation coefficient (TCC) and spatial correlation coefficient (SCC) are both calculated by (1). A high TCC (SCC) value indicates that the hindcast and observed precipitation have significant similarity between their temporal (spatial) variations, while a low RMSE value indicates close agreement between the hindcast and observed precipitation quantities.

The FAR, POD, and ETS values based on a $2 \times 2$ contingency table $(a$ : hindcast $\geq$ threshold and observation $\geq$ threshold events, $b$ : hindcast $\geq$ threshold and observation $<$ threshold events, $c$ : hindcast $<$ threshold and observation $\geq$ threshold events, and $d$ : hindcast $<$ threshold and observation $<$ threshold events) [42] are used to assess the forecast performance of the accumulated ten-day precipitation from the hindcast experiments in detecting rainfall events. The $\mathrm{FAR}=b /(a+b)$ and $\mathrm{POD}=a /(a+c)$ indicate the fraction of rainfall events that are false alarms and correctly detected, respectively. The $\mathrm{ETS}=(a-H e) /(a+b+c-H e)$ measures the overall fraction of rainfall events that are correctly diagnosed by the hindcast experiments. $\mathrm{He}=(a+c)(a+b) / n$, and $n$ represents the total number of observations. $\mathrm{FAR}=0, \mathrm{POD}=1$, and $\mathrm{ETS}=1$ indicate a perfect forecast.

Chen and Lin [43] once proposed a correction method to improve the forecast performance of summer precipitation for the dynamical climate prediction system over China. This method uses the correlation between the ENSO cycle and the model's systematic biases, where the model's systematic biases are divided into three different categories according to the ENSO cycle: El Niño years, La Niña years, and normal years. Then, the three categories of systematic biases are subtracted from the predicted precipitation to obtain the corrected predictand. Based on the method developed by Chen and Lin [43], we plan to 
establish a similar error correction scheme. Because the preceding SST is the signal factor of summer precipitation, this study attempts to correct the hindcast error by using the relationship between the preceding SST and the forecast error for the summer accumulated ten-day precipitation. The ECMWF model subseasonal forecast performance for the accumulated ten-day precipitation from June to August is mainly studied in this paper. Consequently, to correct the hindcast error more effectively, the monthly SST is selected to correct the monthly accumulated ten-day precipitation estimates. The ECMWF S2S model should forecast precipitation starting from May to obtain the subseasonal estimate of the accumulated ten-day precipitation from June to August. Therefore, the monthly SST, which is one month ahead of the precipitation estimate, cannot be obtained when the SST is used to correct the hindcast error. In this case, considering the influence of the preceding global SST on summer precipitation and retaining the memory of SST preferably, this study mainly selects SST, which is two months ahead of the precipitation estimate, as the signal factor.

The error correction scheme of this study is given as follows. First, select the regions where the ECMWF hindcast precipitation should be corrected. Then, calculate the monthly RMSE between the ensemble mean and observed summer accumulated ten-day precipitation for the ECMWF hindcast in these regions. Second, to learn the relationship between the preceding SST and forecast error, calculate the TCC between the monthly RMSE, which is attained from the previous step, and the monthly SST, which is two months ahead of the RMSE (for example, calculate the TCC between the precipitation RMSE of June and the monthly SST of April). Third, select the largest area where the TCC exceeds the 95\% confidence level (TCC $>0.44$ or TCC $<-0.44$ ) as a key SST region. The SST of this key region is calculated into a regional average and then into a standardized SST, where the standardized SST is calculated as follows:

$$
\text { standardized SST }=\frac{X_{t}-\bar{X}}{\sqrt{(1 / T) \sum_{t=1}^{T}\left(X_{t}-\bar{X}\right)^{2}}},
$$

where $X$ is the monthly SST, $t$ refers to each year from 1995 to 2014 , $T$ indicates the number of years from 1995 to 2014 , and $\bar{X}$ is the mean value of $X$ among the Tyears. The SST is standardized to have a mean of zero and a standard deviation of one, where the purpose of standardization is to highlight SST anomalies. Next, according to the standardized SST, the 20 years from 1995 to 2014 are divided into three categories. That is, the years in which the standardized SST is more than 1 are defined as $k=1$; the years in which the standardized SST is less than -1 are defined as $k=2$; and the years in which the standardized SST is more than -1 and less than 1 are defined as $k=3$. Finally, the average error between the ensemble mean and observed summer accumulated ten-day precipitation for the ECMWF hindcast is calculated when $k=1, k=2$, and $k=3$. The formula is given as follows:

$$
\begin{aligned}
& E_{k}=\operatorname{mean}\left(F_{j}-O_{j}\right)_{k}\left\{\begin{array}{l}
k=1 \\
k=2, \\
k=3
\end{array}\right. \\
& F_{j, k}^{*}=F_{j, k}-E_{k},
\end{aligned}
$$

where $F(O)$ is the precipitation of the ECMWF hindcast (observation), $j$ refers to the hindcast point, and $E_{k}$ indicates the average error between the hindcast and observed precipitation when $k=1, k=2$, and $k=3$. In (6), $F_{j, k}^{*}$ and $F_{j, k}$ are the corrected and uncorrected ECMWF hindcast precipitation, respectively.

\section{Results and Discussion}

3.1. ECMWF S2S Hindcast Performance for Summer Subseasonal Precipitation over Eastern China. In this section, the summer subseasonal precipitation hindcast quality of the ECMWF S2S model is evaluated for eastern China. Figure 1 exhibits the spatial distribution of the TCC between the hindcast and observed summer subseasonal precipitation for the ECMWF, JMA, and CMA models during 1995-2010. Obviously, the TCC values drop with an increase in the lead time, which means that the forecast performances of the models weaken as the lead time increases. When the lead times are 15-20 days, the TCC is less than 0 over most of western China, which indicates that the model forfeits its forecast performance in these regions. In addition, the useful forecast skills of the models are considered as the TCC exceeds the 95\% confidence level; the threshold values of the useful forecast skills for the ECMWF and CMA models are both 0.40, and the threshold value for the JMA model is 0.67 . Figure 1 shows that the ECMWF hindcast achieves a useful forecast skill for the summer accumulated ten-day precipitation over most of China at a lead time of approximately 5 days and tends to exhibit the best performance among the three models in China (Figures 1(a)-1(e)). Additionally, the ECMWF model has the best forecast performance in Southeast China, except for the Tibetan Plateau, and the useful forecast skill up to 15 days in some areas of this region. For the JMA hindcast quality, because the sample size of the JMA dataset is small, although the TCC values of the JMA model are high, there are few areas in which the TCC values can exceed the 95\% confidence level (Figures 1(f)-1(j)). The CMA model shows the worst performance among the three models (Figures 1(k)-1(o)). Figures 1(c)-1(e) show that the performance of the ECMWF hindcast experiment is regionally powerful in eastern China at lead times of 10-20 days. That is, the ECMWF hindcast has a comparatively high correlation score in Southeast China, North China, and the eastern half of Northeast China and a relatively low score in the Huaihe River and the western part of Northeast China. Consequently, this paper mainly analyzes the forecast performance of summer subseasonal precipitation for the ECMWF S2S hindcast experiment in eastern China and establishes an error correction scheme to enhance the model's performance. 

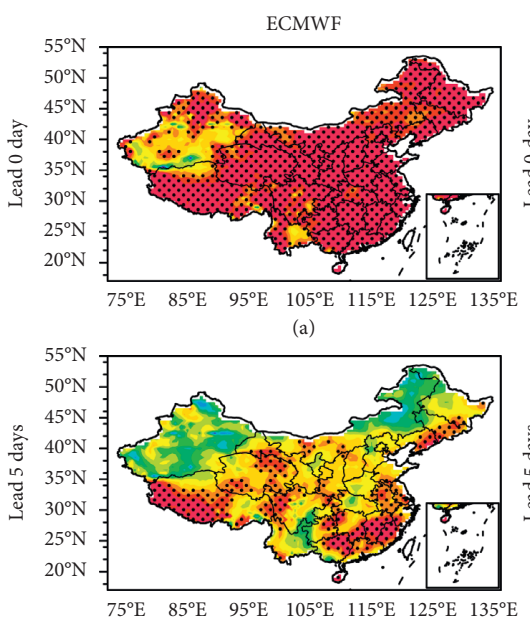

(b)

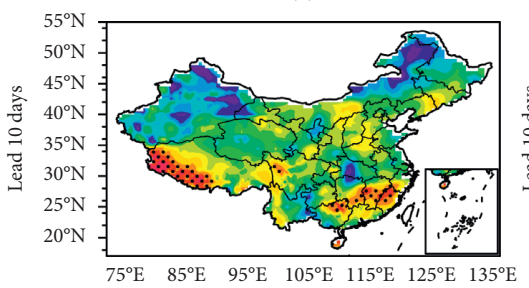

(c)
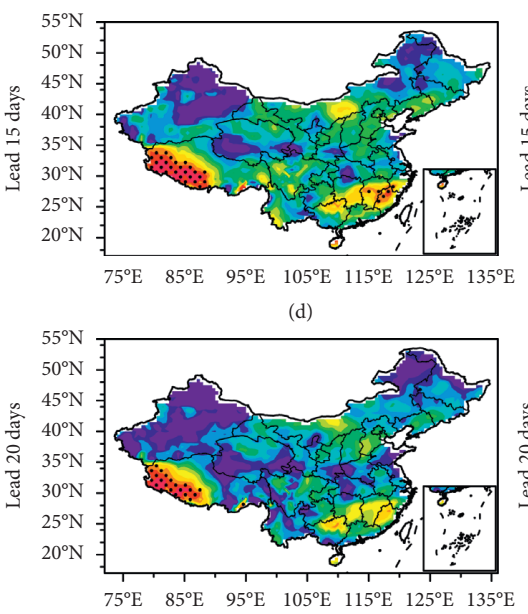

(e)
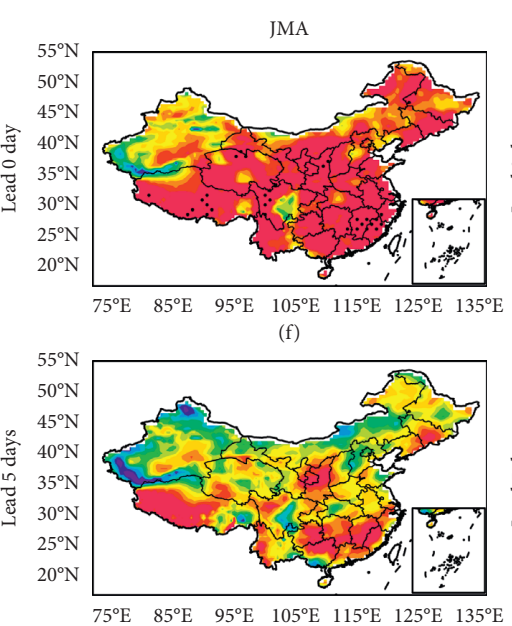

(g)

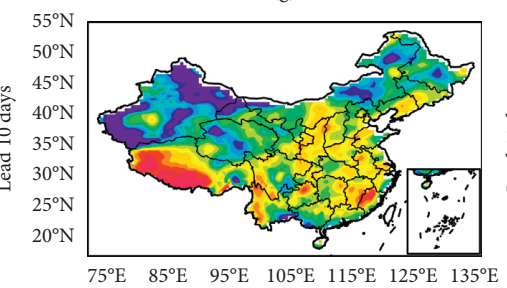

(h)
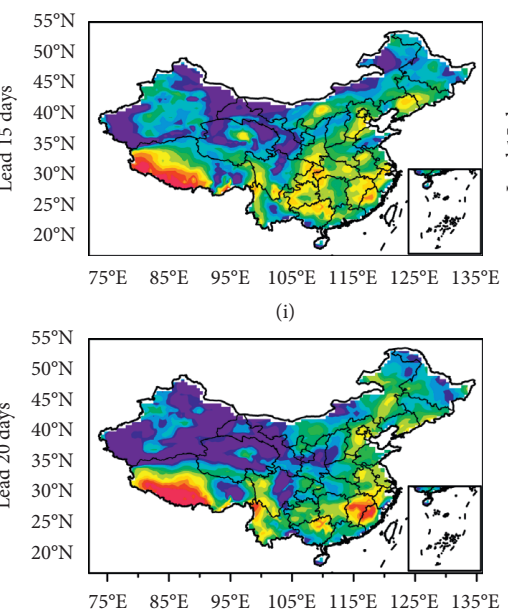

(j)

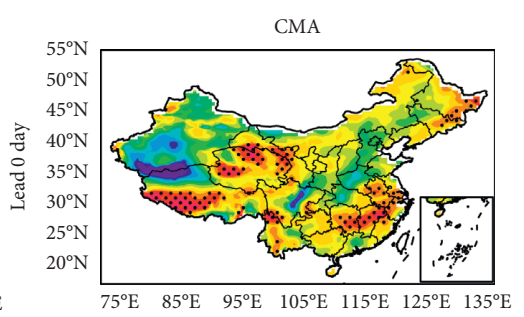

(k)

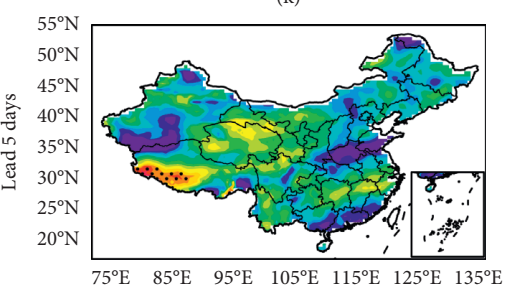

(l)

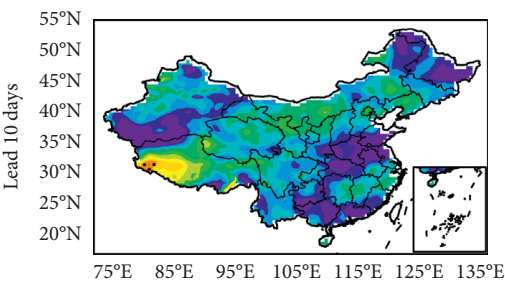

(m)

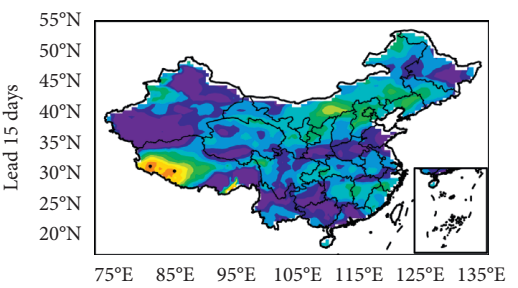

(n)

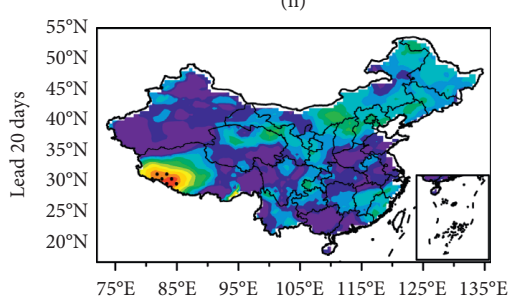

(o)

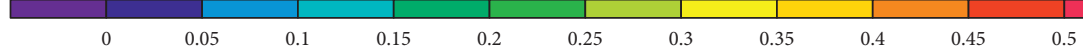

Figure 1: The multiyear average (1995-2010) of the TCC between the ensemble mean and observed summer accumulated ten-day precipitation for ECMWF (a-e), JMA (f-j), and CMA (k-o) S2S hindcast experiments at the lead times of 0, 5, 10, 15, and 20 days in China. The dots represent TCC exceeding 95\% confidence level. The lower right part of the figure is an administrative zoning map of the South China Sea.

According to the above characteristics, the region east of $107^{\circ} \mathrm{E}$ in China can be divided into five subregions. Figure 2 shows these five subregions: Southeast China (Reg1, $18^{\circ} \mathrm{N}-30^{\circ} \mathrm{N}, 107^{\circ} \mathrm{E}-125^{\circ} \mathrm{E}$ ), the Huaihe River Basin (Reg2, $\left.30^{\circ} \mathrm{N}-37^{\circ} \mathrm{N}, 107^{\circ} \mathrm{E}-125^{\circ} \mathrm{E}\right)$, North China (Reg3, $37^{\circ} \mathrm{N}-43^{\circ} \mathrm{N}$, $\left.107^{\circ} \mathrm{E}-125^{\circ} \mathrm{E}\right)$, the western half of Northeast China (Reg4, $\left.43^{\circ} \mathrm{N}-53.5^{\circ} \mathrm{N}, 107^{\circ} \mathrm{E}-125^{\circ} \mathrm{E}\right)$, and the eastern half of Northeast China (Reg5, $\left.40^{\circ} \mathrm{N}-53.5^{\circ} \mathrm{N}, 125^{\circ} \mathrm{E}-135^{\circ} \mathrm{E}\right)$.

When the performance of the ECMWF hindcast is compared to the performance of the JMA and CMA hindcasts, the lead times are $0-20$ days because the JMA hindcast time range is $0-33$ days and the hindcast is processed as the accumulated ten-day precipitation in the future. Hence, when the performance of the ECMWF hindcast is analyzed separately, increased lead times up to 30 days are allowed. To reveal the interannual variation of the ECMWF S2S hindcast performance, the variations in the TCC between the ECMWF ensemble mean and observed summer accumulated ten-day precipitation with time in the five subregions of eastern China (Reg1-Reg5) at the different 


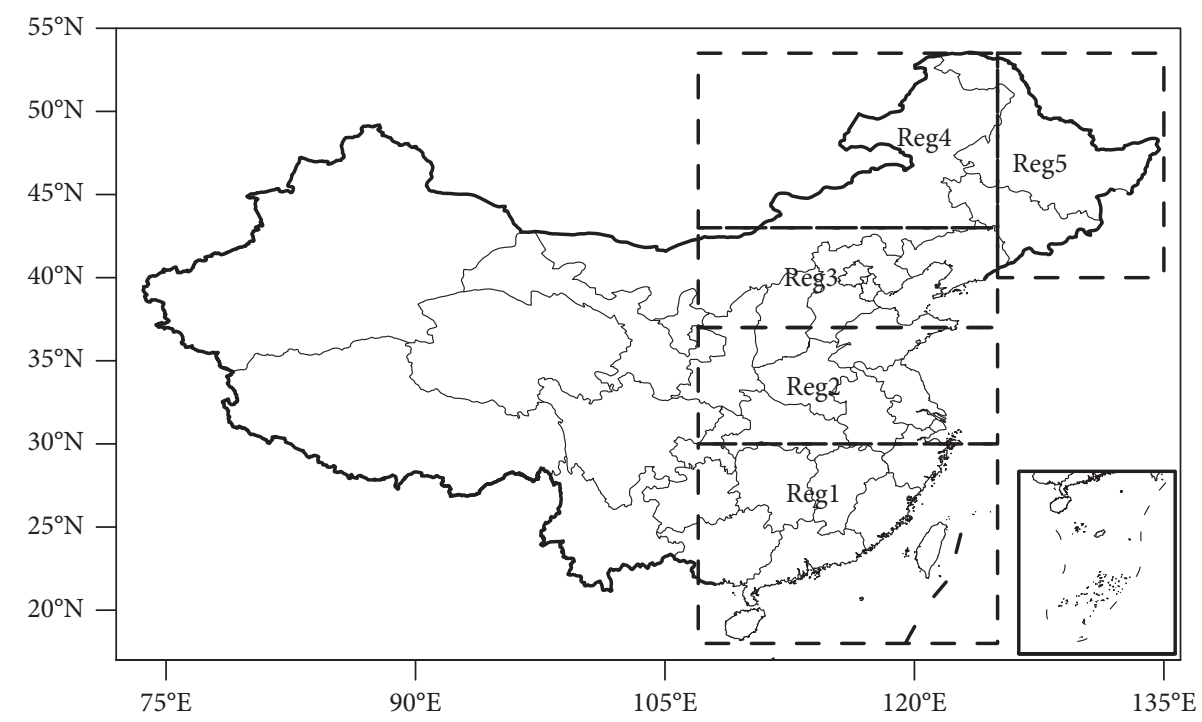

Figure 2: The region east of $107^{\circ} \mathrm{E}$ in China is divided into five subregions which are denoted by the black dashed rectangles. The lower right part of the figure is an administrative zoning map of the South China Sea.

forecast lead times are shown in Figure 3. The TCC values of the ECMWF S2S model all have strong interannual differences in the five subregions. This means that the performance of the ECMWF hindcast is comparatively superior in some years, while in other years, the performance is relatively weak. For example, in Southeast China (Reg1), the TCC values exceed 0.3 at a lead time of 20 days in 2003,2007, 2010, and 2013; however, the TCC values are lower than 0.3 at a lead time of 6 days in 1997, 2002, and 2006 (Figure 3(a)). In addition, the years in which the ECMWF hindcast displays a relatively superior performance are different among the five subregions.

3.2. Forecast Error Correction of the ECMWF Hindcast. After evaluating the detailed features of the ECMWF hindcast performance in the five subregions of eastern China, it is obvious that the hindcast performance of the ECMWF model has considerable deficiencies and should be further enhanced. Accordingly, correcting the forecast error of the ECMWF hindcast is crucial. The error correction scheme employed for this purpose is shown in Section 2.2.

Based on the first and second steps of the proposed error correction scheme, the TCC between the monthly precipitation RMSE and monthly SST at lead times of 0,5 , and 10 days in Southeast China (Reg1) is given in Figure 4, and the SST is two months ahead of the RMSE. This figure reveals a high correlation between the monthly RMSE and the two preceding months of SST. The spatial distributions of the TCC in Reg1 at the other lead times and those in Reg2-Reg5 at the lead times of $0-30$ days are not given. It is evident that the high-correlation areas (TCC exceeding the 95\% confidence level) are different regardless of which variable (the lead time, subregion, or month) is changed. For example, Figure 4(a) shows that there is a significant positive correlation (TCC >0.44) between the June RMSE of the accumulated ten-day precipitation in Southeast China (Reg1) and the April SST in the eastern Pacific Ocean. This result indicates that the June RMSE of precipitation is high in Southeast China (Reg1) when the April SST is abnormally warm in the eastern Pacific Ocean. This high correlation reveals a strong interaction between the monthly RMSE of precipitation and the two preceding months of SST. Chen and Lin [43] utilized the correlation between the ENSO cycle and their studied model's systematic biases to correct the forecast error. Consequently, according to the high correlation between the precipitation RMSE and two preceding months of SST, the forecast error for the summer accumulated ten-day precipitation can be corrected by the preceding SST. Then, the largest area where the TCC exceeds the $95 \%$ confidence level is selected as a key region of the preceding SST to correct forecast error; the black rectangles in Figure 4 represent the key regions. To correct the forecast error effectively, the precipitation RMSE should be classified. Because the preceding SST anomalies of key regions can cause precipitation RMSE anomalies, the preceding SST anomalies are classified first to achieve the classification of the precipitation RMSE. The preceding SST is calculated by (4) to obtain the standardized SST and reveal the preceding SST anomaly. In this paper, the standardized SST is classified into three categories, which are described in Section 2.2. Based on these three standardized SST categories, the average error between the hindcasts and observations for each category is calculated; the formula is shown in (5). Finally, the average errors of the three categories are subtracted from the ECMWF hindcast to obtain the corrected hindcast precipitation.

3.3. Summer Subseasonal Precipitation Forecast Performance of the Error-Corrected ECMWF S2S Model Experiment in Eastern China. Based on the abovementioned error correction scheme, the ensemble mean summer subseasonal precipitation estimated from the ECMWF S2S hindcast 


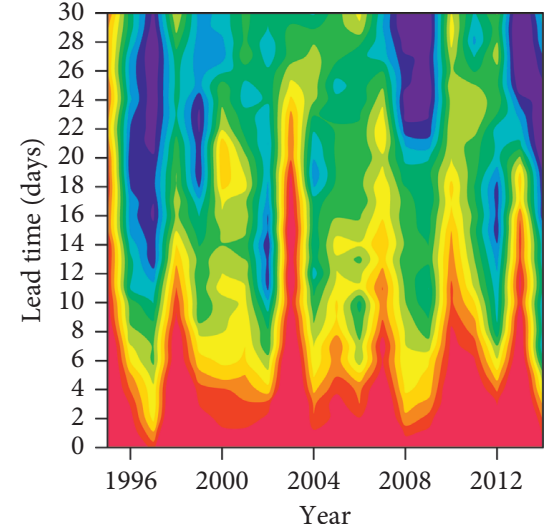

(a)

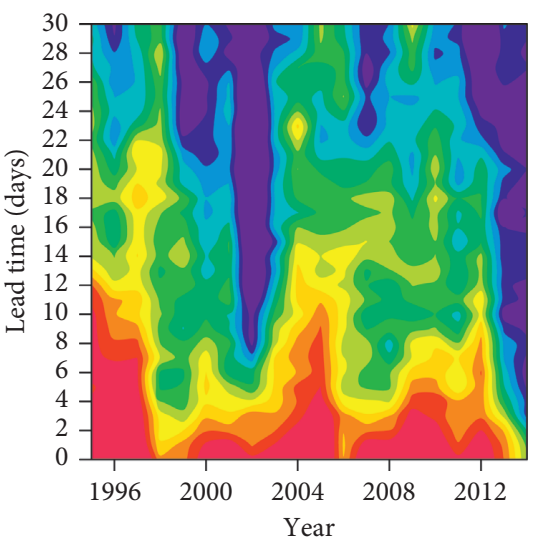

(c)

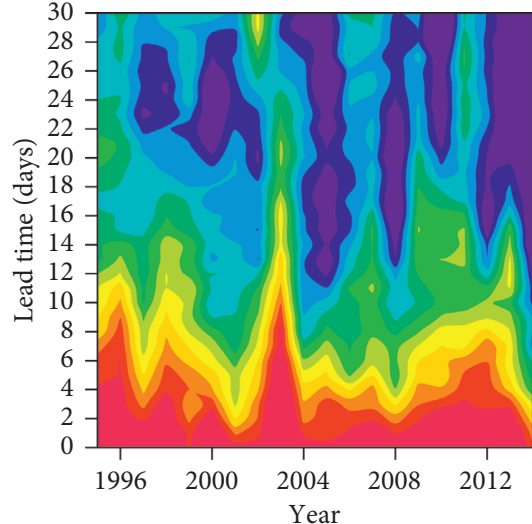

(b)

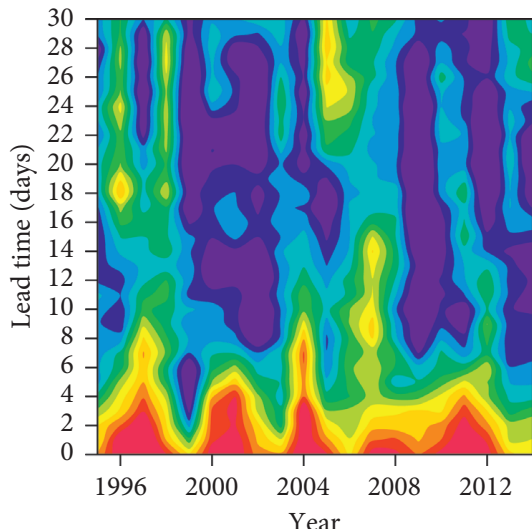

(d)

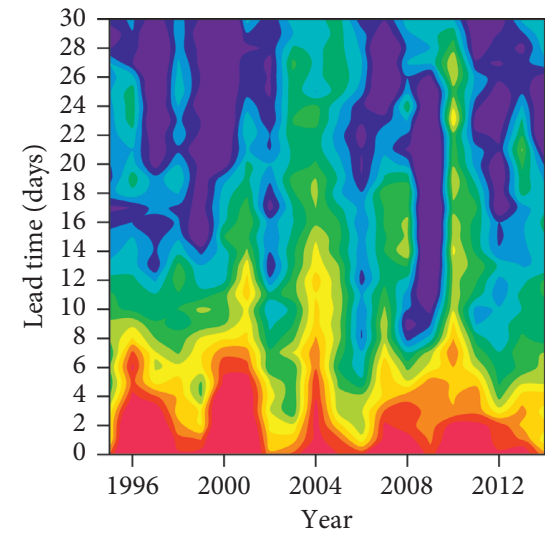

(e)

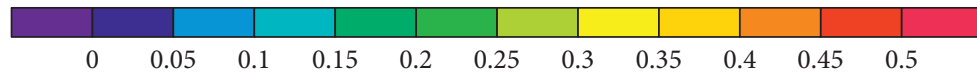

FIGURE 3: Interannual variation (1995-2014) of the TCC between the ensemble mean and observed summer accumulated ten-day precipitation for ECMWF S2S hindcast experiment at the lead times of 0-30 days in five subregions (a-e) of eastern China. (a) Reg1, (b) Reg2, (c) Reg3, (d) Reg4, and (e) Reg5.

experiment at lead times of $0-30$ days in the five subregions of eastern China was corrected. Consistent with the assessment of the performance of the three S2S hindcast experiments, the spatial distribution of the TCC is adopted to evaluate the summer subseasonal precipitation forecast performance of the error-corrected ECMWF hindcast. Because Figure 1 shows the TCC of the ECMWF hindcast only at lead times of 0-20 days, to compare the performance of the ECMWF S2S hindcasts with and without error corrections at lead times of 0-30 days in eastern China, Figure 5 displays not only the TCC of the corrected ECMWF S2S hindcast at those lead times in eastern China but also the TCC of the uncorrected ECMWF. The TCC values between the ensemble mean and observed precipitation for the 

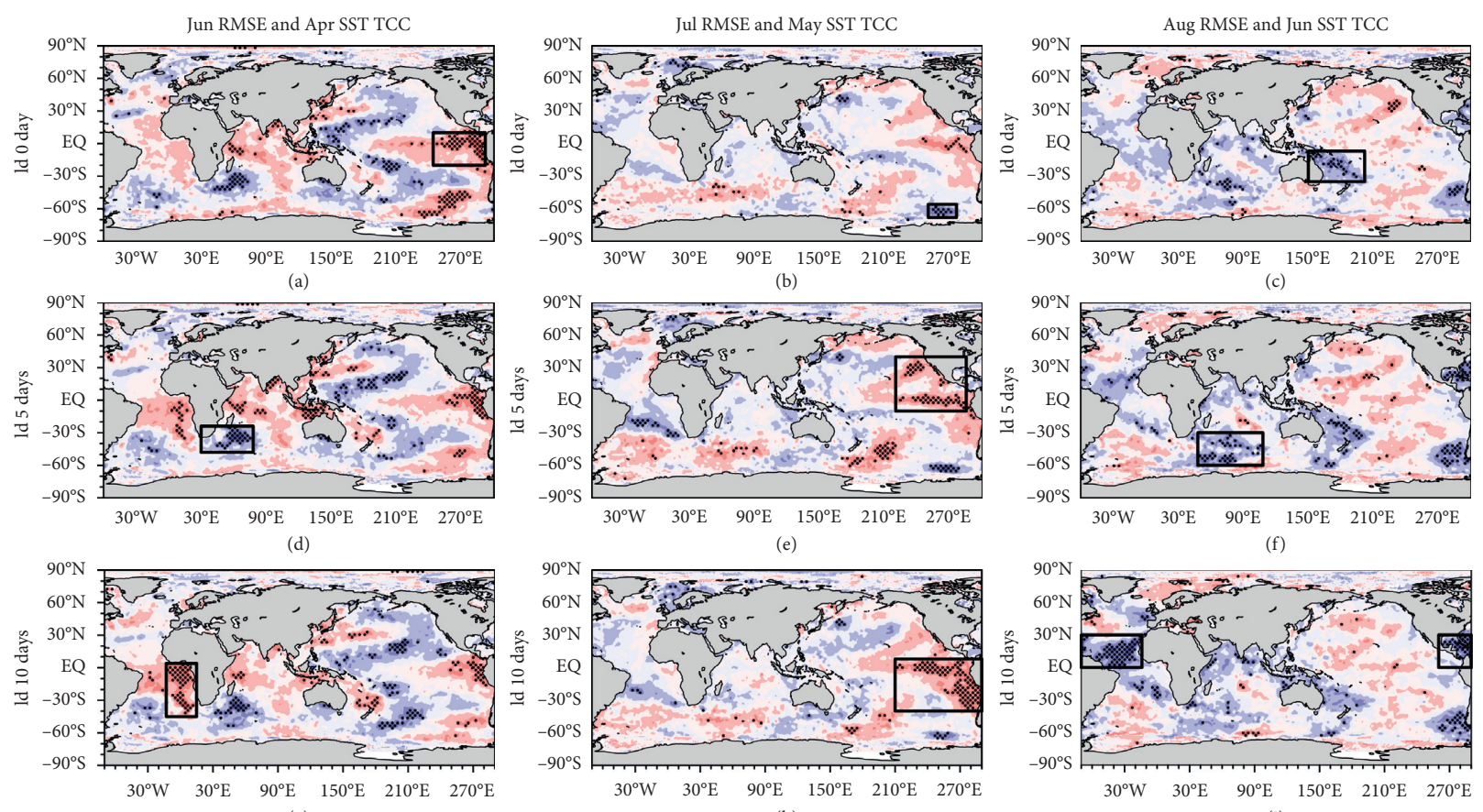

(g)

(h)

(i)

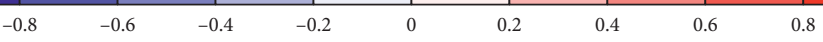

FIGURE 4: The spatial distribution of TCC (1995-2014) between southeast China (Reg1) monthly RMSE and monthly SST which is two months ahead of RMSE at the lead times of 0 , 5, and 10 days. (a, d, g) The TCC between the RMSE of Jun and the SST of Apr (b, e, h) The TCC between the RMSE of Jul and the SST of May. (c, f, i) The TCC between the RMSE of Aug and the SST of Jun. The monthly RMSE is calculated by the ensemble mean and observed summer accumulated ten-day precipitation for ECMWF hindcast experiment. The dots represent TCC exceeding 95\% confidence level; the black rectangles stand for key regions of SST.

ECMWF hindcast are similar to the TCC values between the corrected and observed precipitation for the ECMWF hindcast at lead times of 0-5 days in eastern China. This result reveals that the performance of the error-corrected ECMWF hindcast is only slightly better than that of the uncorrected hindcast at lead times of $0-5$ days, which may be because the performance of the uncorrected ECMWF hindcast experiment is excellent at lead times of 0-5 days. Before the error correction, there is a negative correlation between the ensemble mean and observed summer accumulated ten-day precipitation for the ECMWF S2S hindcast experiment at lead times of 10-30 days in some regions of eastern China. However, the negative TCC values are increased to 0.1-0.2 after correcting the forecast error. In Southeast China (Reg1), the TCC regions exceeding the 95\% confidence level are expanded after the error correction at lead times of 10-30 days. In addition, the useful forecast skill of the ECMWF hindcast increases from 15 days to 30 days after correcting the forecast error in some areas of Southeast China (Reg1). After correcting the forecast error at lead times of 10-30 days, it is obvious that the hindcast performance of the ECMWF model is significantly enhanced, and most regions show a correlation score of approximately 0.2-0.3.

The RMSE is a measure of the ECMWF hindcast accuracy that reveals forecast deficiencies that the TCC does not indicate. The spatial distributions of the RMSE for the
ECMWF hindcasts with and without error corrections obtained by comparing the summer accumulated ten-day precipitation from the observation data at different lead times over the period of 1995-2014 in eastern China is exhibited in Figure 6. It is obvious that the RMSE values gradually increase with increasing lead time, especially in Southeast China (Reg1). In addition, the ECMWF hindcasts with and without error corrections show significantly similar spatial distributions of the RMSE. The RMSE values decrease from southeast to northwest in eastern China; this pattern may arise because the forecast error of the ECMWF hindcast is proportional to the magnitude of the precipitation rate $[44,45]$. Comparing the RMSE for the ECMWF hindcast experiments with and without error corrections, it can be found that the RMSE values decrease obviously after correcting the ECMWF hindcast error. This result indicates that the performance of the ECMWF hindcast is improved after correcting for the forecast error. Overall, according to the spatial distributions of the TCC and RMSE, the error-corrected ECMWF hindcast exhibits higher agreement with the observed summer accumulated ten-day precipitation than the ECMWF hindcast without an error correction with regard to the quantity and temporal variation of precipitation over eastern China. This result reveals that adopting the preceding SST to correct the summer subseasonal precipitation for the ECMWF hindcast is feasible. 

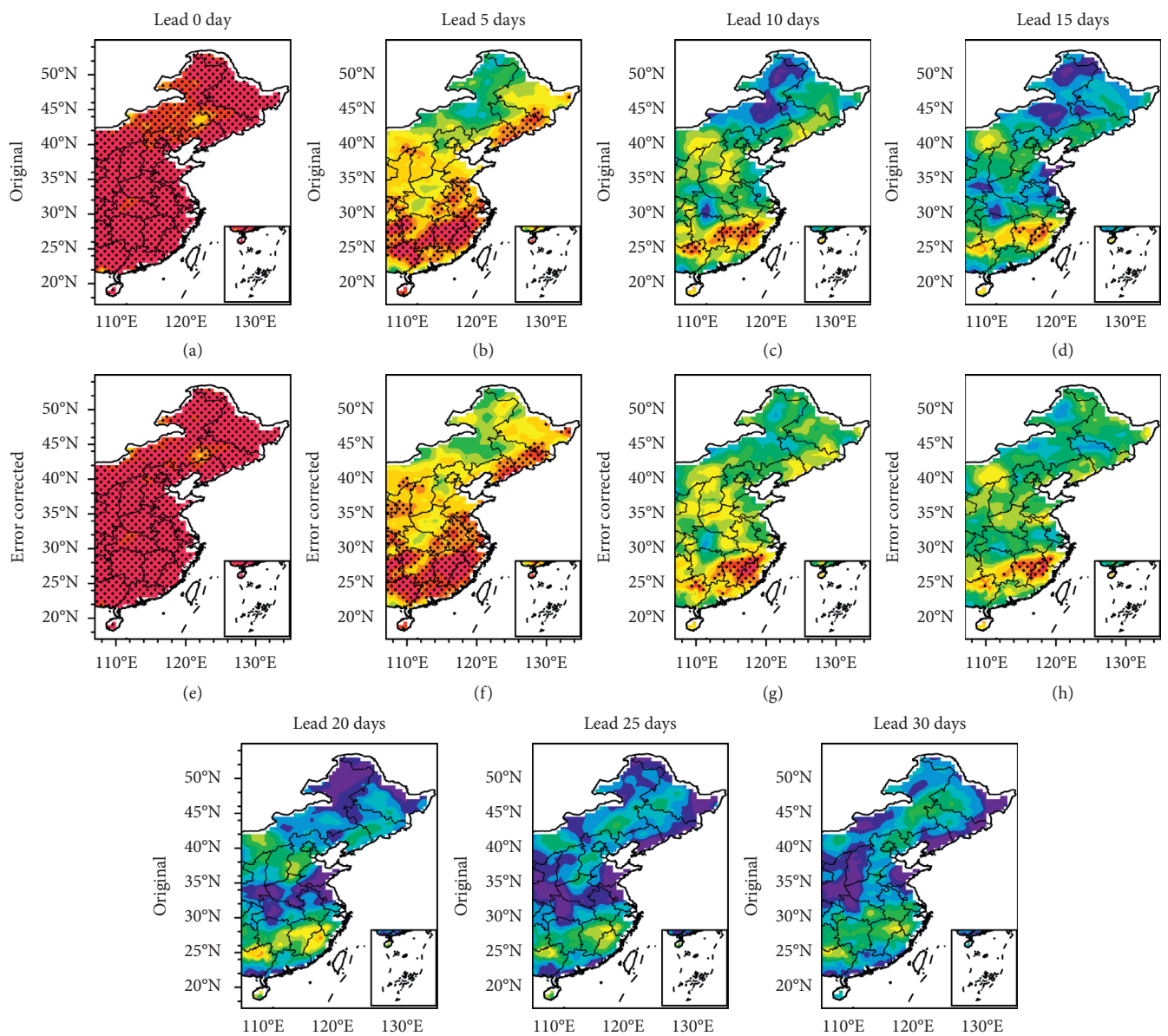

(f)

(g)

(h)
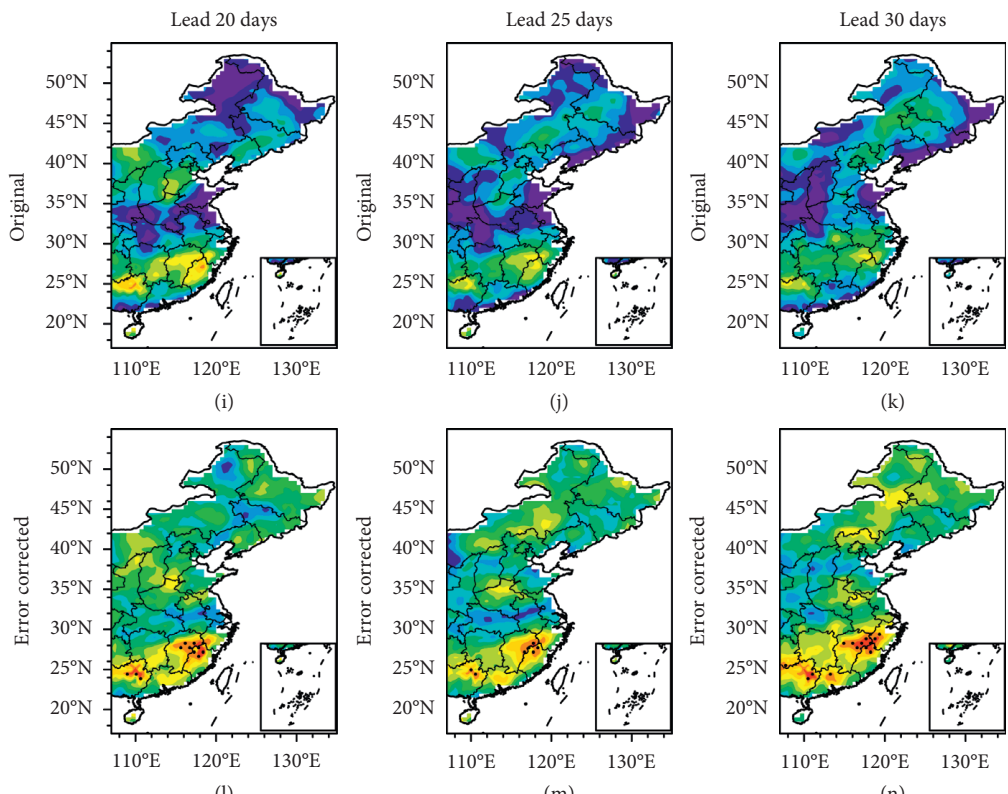

(k)

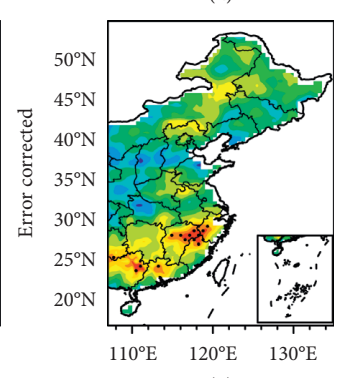

(m)

(n)

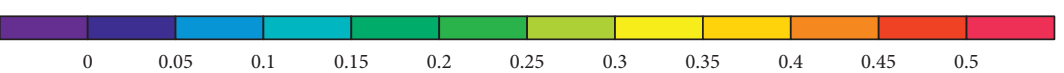

FIGURE 5: The multiyear average (1995-2014) of the TCC between the ensemble mean and observed summer accumulated ten-day precipitation for error-uncorrected (a-d and $\mathrm{i}-\mathrm{k}$ ) and error-corrected (e-h and $\mathrm{l}-\mathrm{n}$ ) ECMWF S2S hindcast experiment with lead times of 0 , $5,10,15,20,25$, and 30 days in the eastern China. The dots represent TCC exceeding 95\% confidence level. The lower right part of the figure is an administrative zoning map of the South China Sea.

To reveal the difference in the interannual variation performance between the ECMWF hindcasts with and without error corrections, the interannual variations (1995-2014) of the TCC between the error-corrected and observed precipitation for the ECMWF hindcast at lead times of 0-30 days in the five subregions of eastern China are shown in Figure 7. Comparing Figures 3 and 7, it is not difficult to find that the performance of the ECMWF hindcast is improved after correcting the forecast error. However, the performance of the error-corrected ECMWF hindcast also has a strong interannual difference. The TCC values of the ECMWF hindcasts without an error correction are low in some years, and the TCC values are still relatively low in those years after correcting the forecast error. Conversely, the years with high TCC values have higher TCC values after correcting the error. Although the TCC values are enhanced in most years at lead times of 0-30 days over the five subregions, the correlation scores are similar for the ECMWF hindcasts with and without error corrections in some years. For example, the TCC value is similar for the 


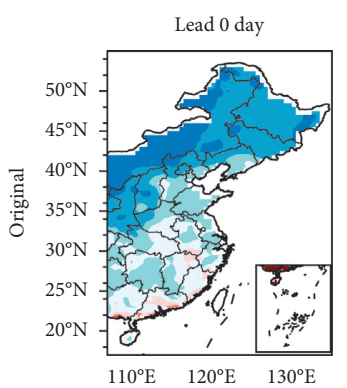

(a)

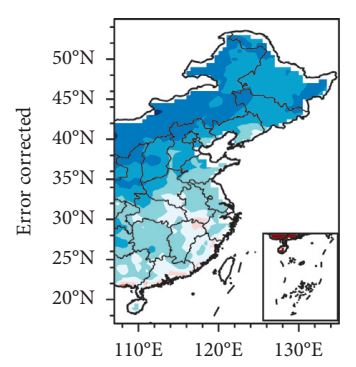

(e)

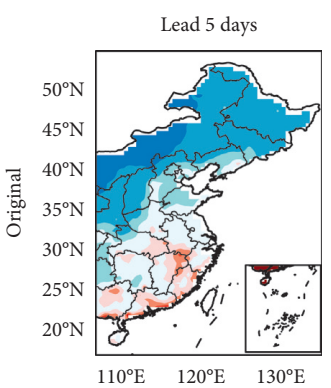

(b)

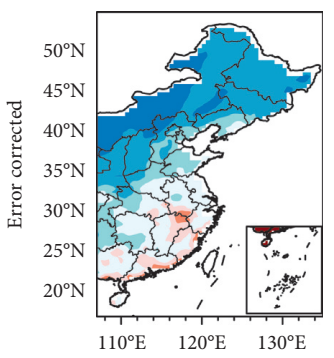

(f)

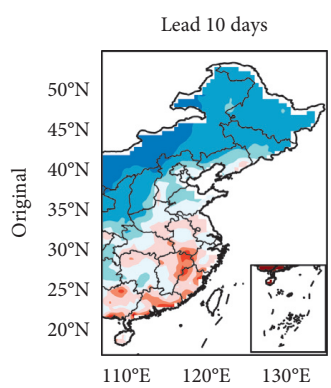

(c)

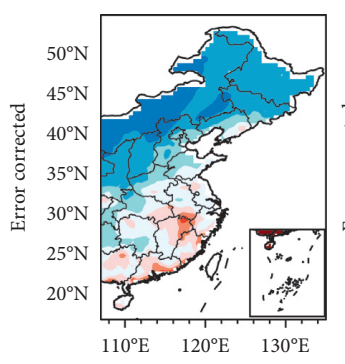

(g)

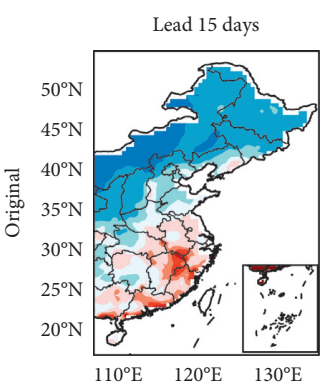

(d)

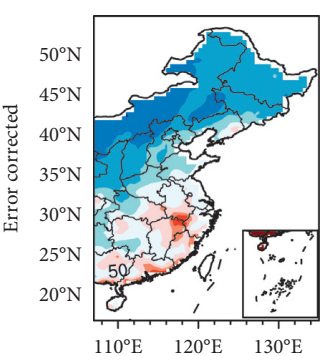

(h)
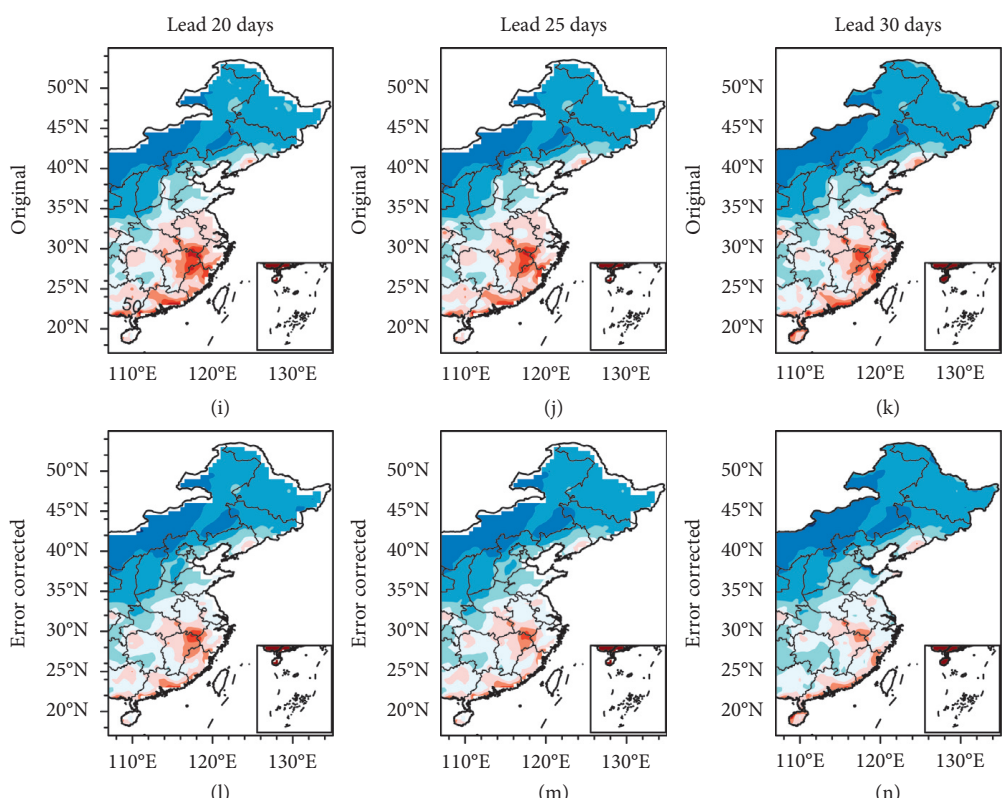

(1)

(m)

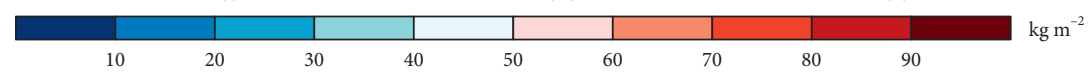

Figure 6: As in Figure 5, but for RMSE.

ECMWF hindcasts with and without error corrections in 2009 over the western part of Northeast China (Reg4).

Figure 8 shows that the TCC between the ECMWF hindcast and the observed summer accumulated ten-day precipitation with and without error corrections changes with the lead time in the five subregions of eastern China during 1995-2014. This figure reveals that the forecast performance of both ECMWF hindcasts (with and without error corrections) drops with an increase in the lead time in each subregion. Comparing the variation curves of the TCC values for the ECMWF hindcasts with and without error corrections, we discover similar change trends and that the TCC values for the error-corrected hindcasts are higher than those for the hindcasts without error corrections at lead times of 0-30 days. Moreover, after the hindcast precipitation is corrected, the TCC values increase more distinctly as the lead time increases. Although the useful forecast skill (TCC 0.4) of the error-corrected hindcast only increases by 1-2 days compared to the uncorrected hindcast and is limited to 8 days in every subregion (Figure 8), the forecast skill increases by approximately 15 days in some parts of Southeast China (Reg1) (Figure 5). In addition, the TCC values of the uncorrected ECMWF hindcast are less than 0.1 at lead times of 15-30 days in the Huaihe River (Reg2) and Northeast China (Reg4 and Reg5), while the TCC can approach a relatively high value of 0.2 after correcting the 


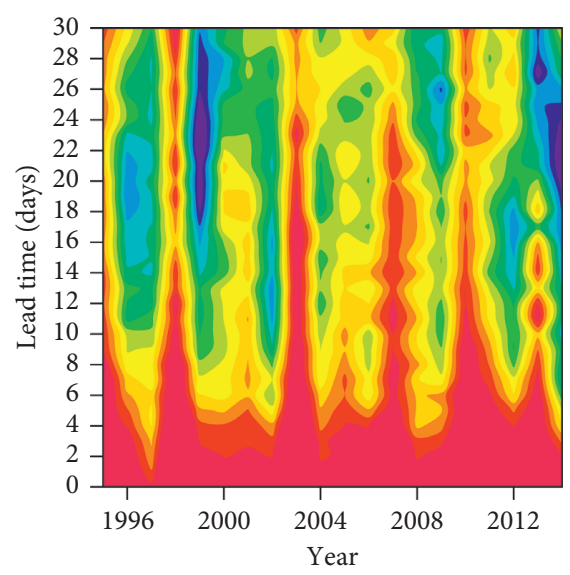

(a)

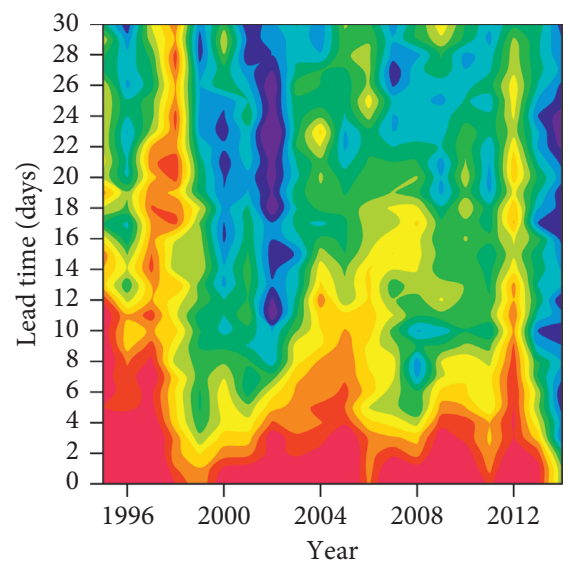

(c)

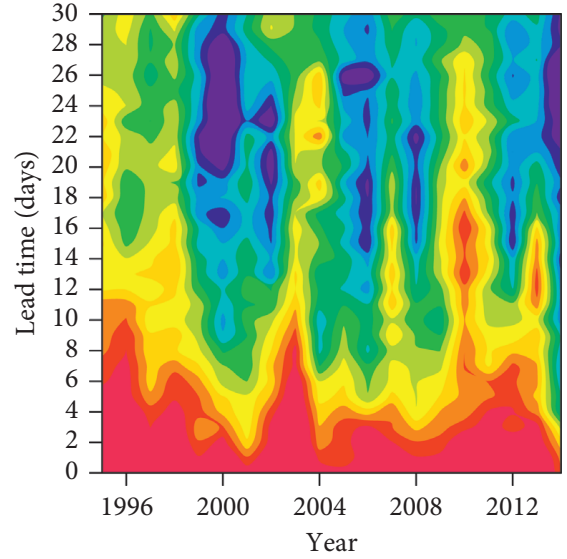

(b)

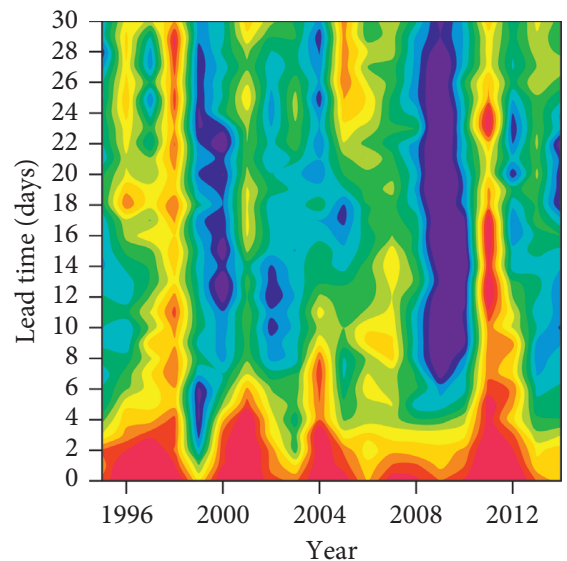

(d)

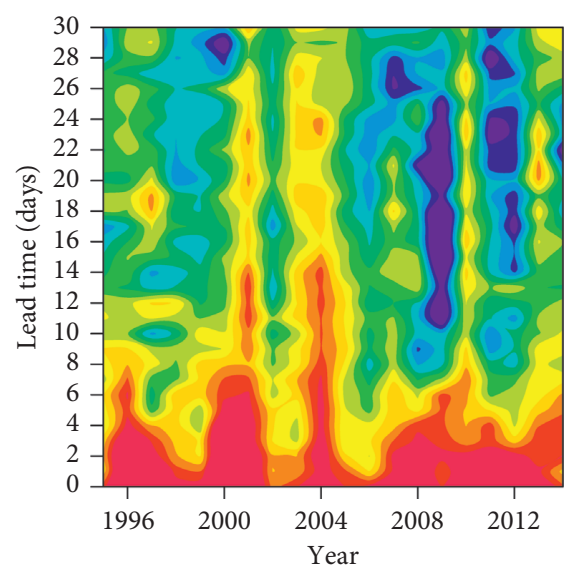

(e)

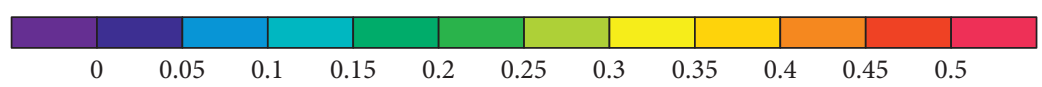

Figure 7: As in Figure 3, but for error-corrected ECMWF hindcast. (a) Reg1, (b) Reg2, (c) Reg3, (d) Reg4, and (e) Reg5.

forecast error. The forecast skill with TCC values of $0.15 \sim 0.2$ is enhanced $(0.25 \sim 0.3)$ in Southeast China (Reg1) at lead times of 20-30 days, while the skill increases least significantly in North China (Reg3) after the forecast error correction.

The changes in the forecast performance of the uncorrected and corrected ECMWF hindcasts with the lead time in depicting the quantity of precipitation are shown in Figure 9. From Figure 9, the standardized RMSE values between the ensemble mean and observed summer accumulated ten-day precipitation for the ECMWF S2S hindcasts decrease to a certain degree after correcting the hindcast error. This means that the performance of the ECMWF hindcast is improved after correcting the forecast error. 


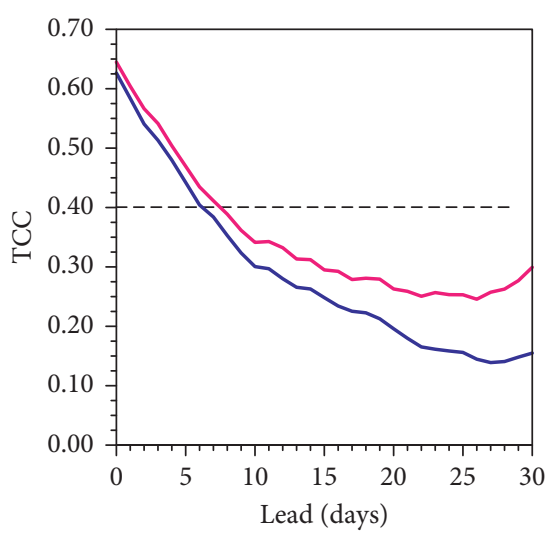

Error corrected Original

(a)

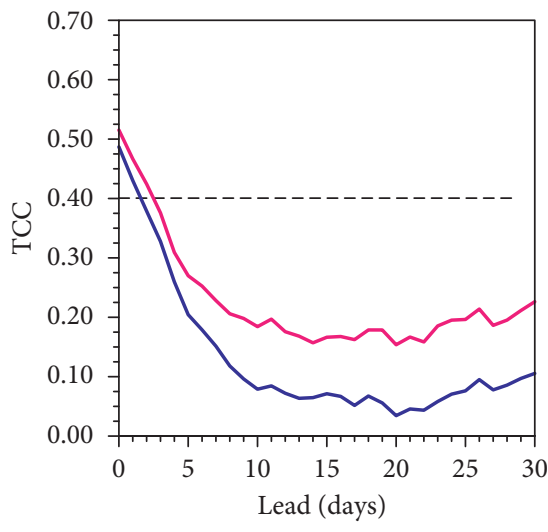

Error corrected

Original

(d)

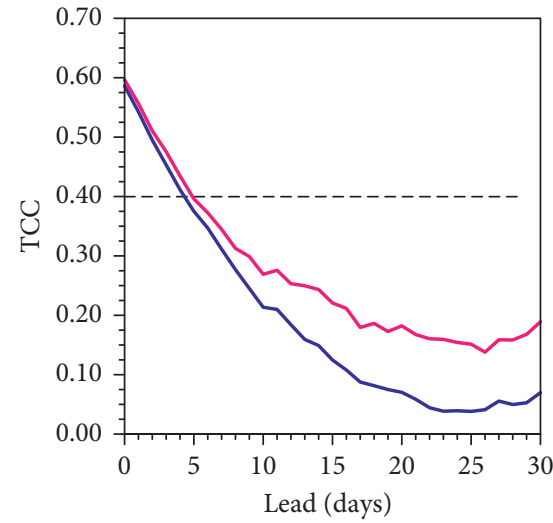

Error corrected Original

(b)

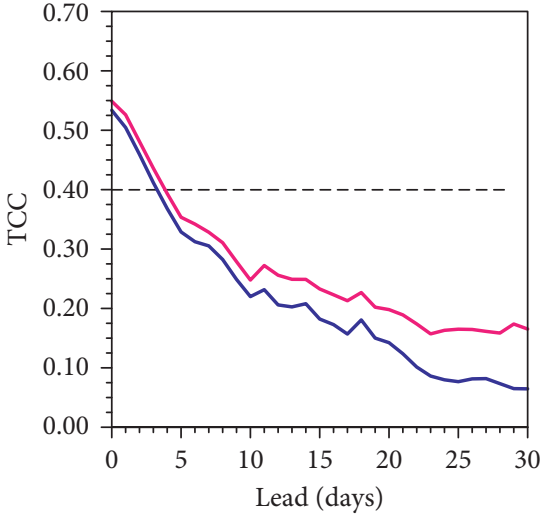

Error corrected Original

(c)

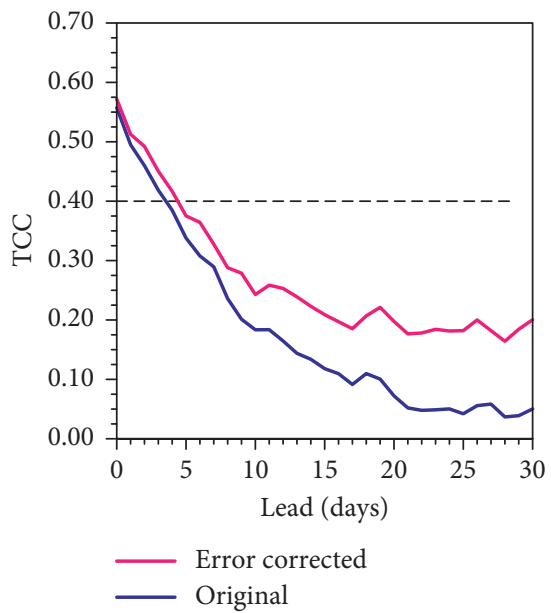

(e)

Figure 8: The TCC between the ensemble mean and observed summer accumulated ten-day precipitation for error-uncorrected and errorcorrected ECMWF S2S hindcast experiment changing with the lead time (0-30 days) in five subregions of eastern China (a-e) during 1995-2014. The black dashed line is 95\% confidence level of TCC. (a) Reg1, (b) Reg2, (c) Reg3, (d) Reg4, and (e) Reg5.

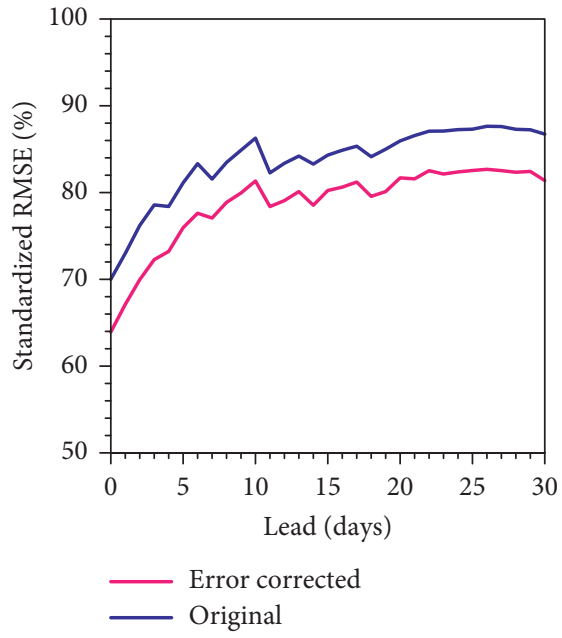

(a)

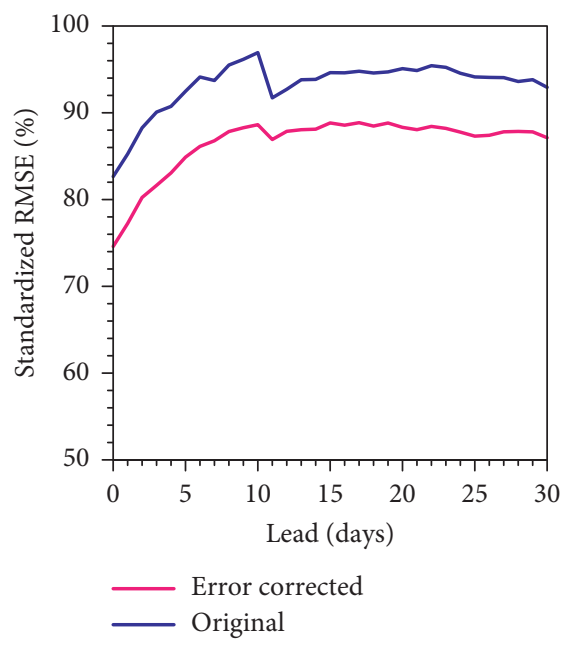

(b)

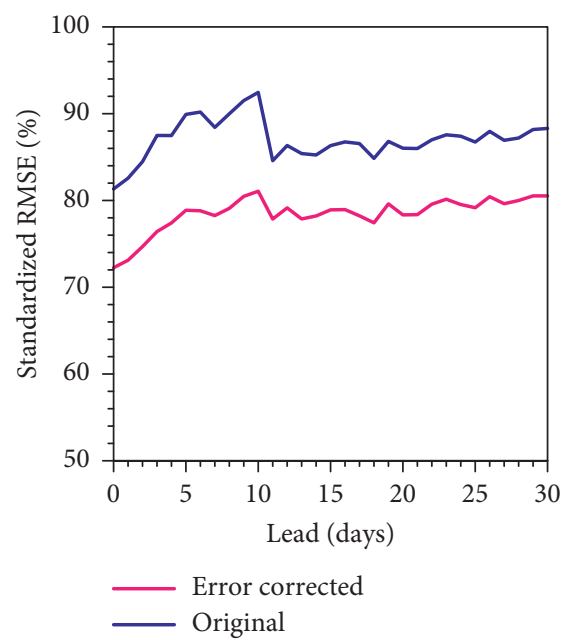

(c)

Figure 9: Continued. 


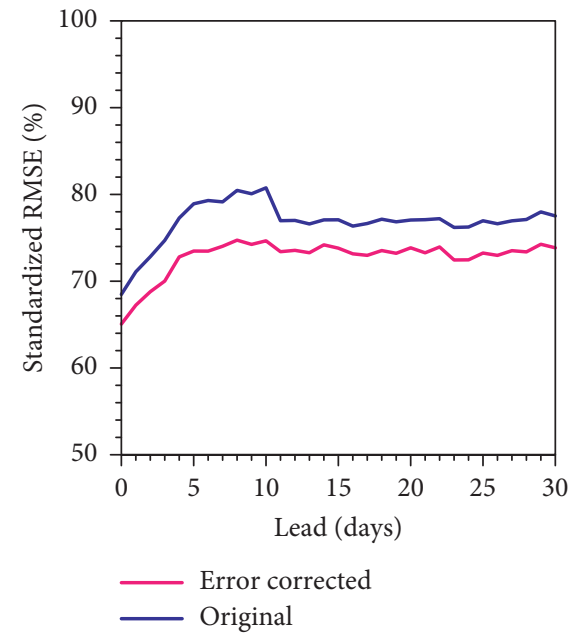

(d)

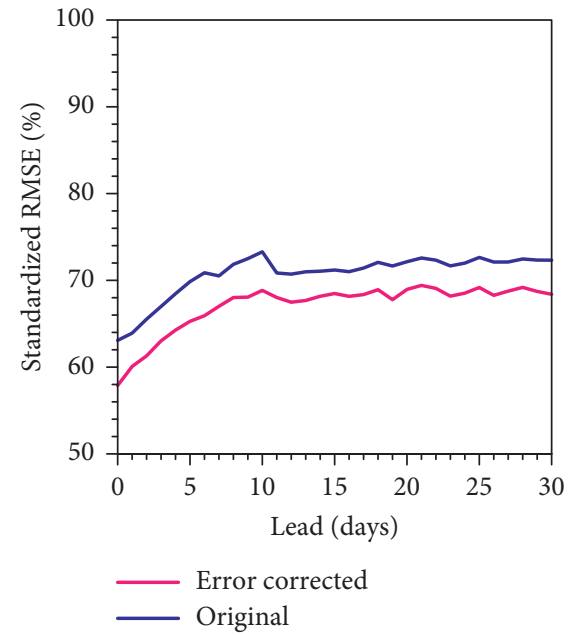

(e)

Figure 9: As in Figure 8, but for standardized RMSE. (a) Reg1, (b) Reg2, (c) Reg3, (d) Reg4, and (e) Reg5.

Additionally, Figure 9 exhibits significantly less forecast error in the eastern part of Northeast China (Reg5) than in the other four subregions. The standardized RMSE values exhibit the greatest decrease in North China (Reg3) and the smallest decrease in the eastern part of Northeast China (Reg5) after correcting the forecast error. In addition, the change trend of the standardized RMSE values for the uncorrected ECMWF hindcast is slightly consistent with that for the corrected ECMWF hindcast at lead times of $0-30$ days.

The performance of the ECMWF hindcasts with and without error corrections has been evaluated by describing the agreement between the hindcasts and observations with regard to the temporal variation and quantity of precipitation. Figure 10 exhibits the SCC between the ensemble mean and observed summer accumulated ten-day precipitation for the uncorrected and corrected ECMWF S2S hindcasts. This figure shows the agreement between the hindcasts and observations regarding the spatial variation of precipitation at lead times of 0-30 days. The SCC values increase after correcting the forecast error, which indicates that the performance of the ECMWF hindcast is pronouncedly improved in depicting the agreement in the spatial variation between the hindcasts and observations. Although the SCC values exhibit greater increases in Southeast China (Reg1) and the Huaihe River (Reg2), relatively high SCC values are observed in North China (Reg3) after correcting the forecast error at lead times of 0-30 days.

To evaluate the performance of the uncorrected and corrected ECMWF hindcasts for different precipitation rates, Figure 11 shows the results of the FAR, POD, and ETS with different accumulated ten-day precipitation thresholds for the uncorrected and corrected hindcasts in the five subregions of eastern China during 1995-2014. According to the different precipitation rates of the five subregions, the ranges of the accumulated ten-day precipitation threshold are different among these subregions. The precipitation thresholds of Southeast China (Reg1) are 10, 20, 50, 100, and
$150 \mathrm{~mm}$, while the thresholds of the Huaihe River (Reg2), North China (Reg3), and the eastern half of Northeast China (Reg5) are all 10, 20, 50, and $100 \mathrm{~mm}$, and the thresholds of the western half of Northeast China (Reg4) are 10, 20, and $50 \mathrm{~mm}$. For the FAR (Figures 11(a)-11(e)), the scores increase with increasing lead time, especially when the precipitation threshold exceeds $20 \mathrm{~mm}$. In addition, the uncorrected ECMWF hindcast results in increasing FAR scores with an increasing threshold, and the forecast skill is the worst for thresholds greater than $20 \sim 50 \mathrm{~mm}$. Comparing the FAR scores of the five subregions under the same threshold, the scores are the lowest in Southeast China (Reg1), so the skill of the ECMWF hindcast is the best in this subregion. After correcting the forecast error, the FAR scores decrease, and the decrease is more obvious for thresholds greater than $20 \mathrm{~mm}$. For the POD (Figures 11(f)$11(\mathrm{j}))$, the scores gradually decrease with increasing lead time, especially when the precipitation threshold exceeds $20 \mathrm{~mm}$. The forecast skill of the ECMWF hindcast decreases with increasing lead time. Additionally, the hindcast results in decreasing POD scores with an increasing threshold, and the scores are the worst for thresholds greater than 20 50 mm. Consistent with the analysis of the FAR score, the POD scores also show a better hindcast skill in Southeast China (Reg1) than in the other subregions. The POD scores are enhanced after correcting the forecast error, and the increment is more obvious for thresholds greater than $20 \mathrm{~mm}$. However, there are also some instances in which the POD scores decrease after correction; for example, the scores for the corrected hindcast are lower than those for the uncorrected hindcast in North China (Reg3) when the thresholds are 20 and $50 \mathrm{~mm}$. For the ETS (Figures 11(k)11(o)), the forecast skill of the hindcast decreases as the lead time increases. The skill of the uncorrected hindcast is low for low precipitation thresholds (thresholds $<20 \mathrm{~mm}$ ) in each of the five subregions, and the skill is also low for high thresholds (thresholds $>50 \mathrm{~mm}$ ) in Southeast China (Reg1) and North China (Reg3). In addition, the ETS scores reveal 


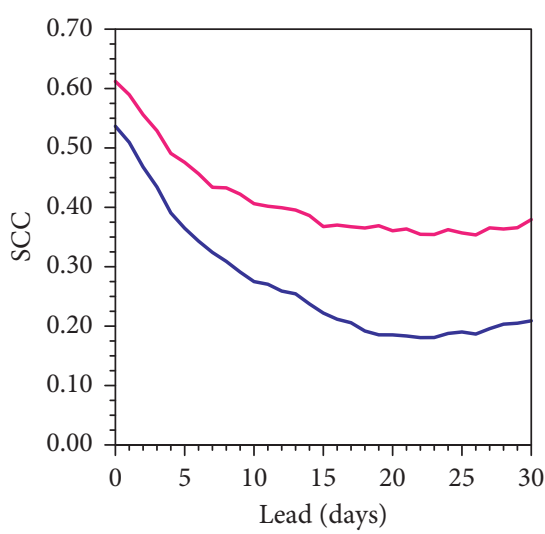

Error corrected Original

(a)

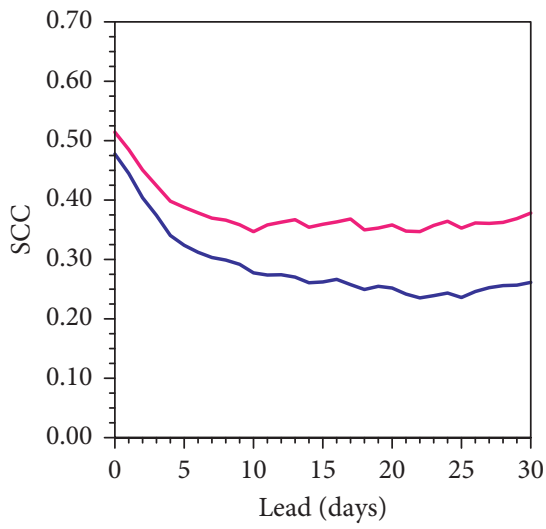

Error corrected

Original

(d)

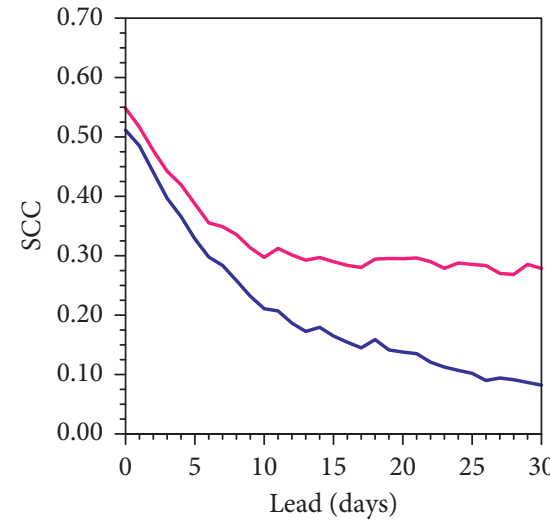

Error corrected Original

(b)

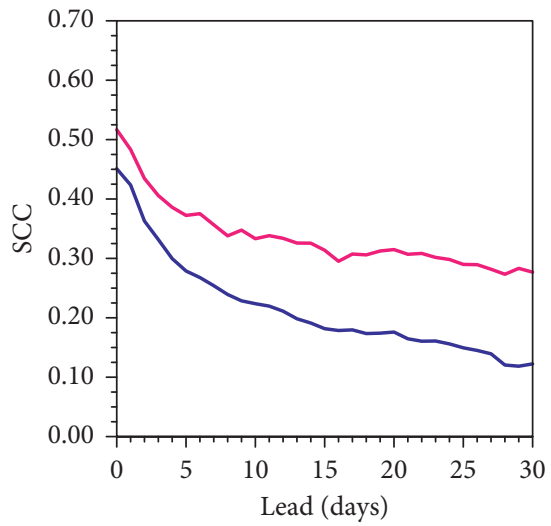

Error corrected

Original

(e)

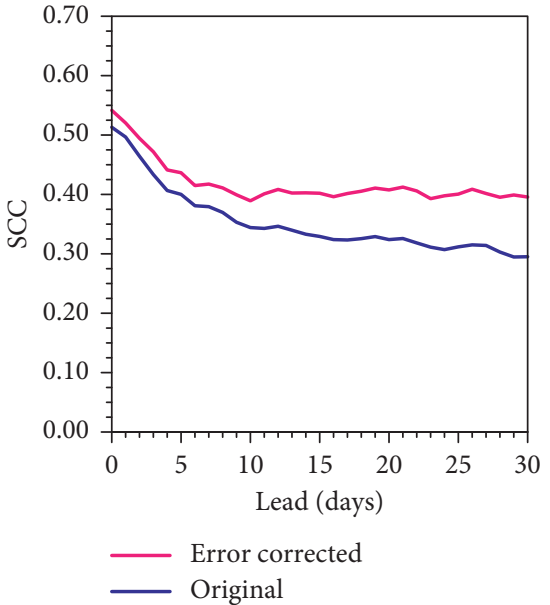

(c)

Figure 10: As in Figure 8, but for SCC. (a) Reg1, (b) Reg2, (c) Reg3, (d) Reg4, and (e) Reg5.
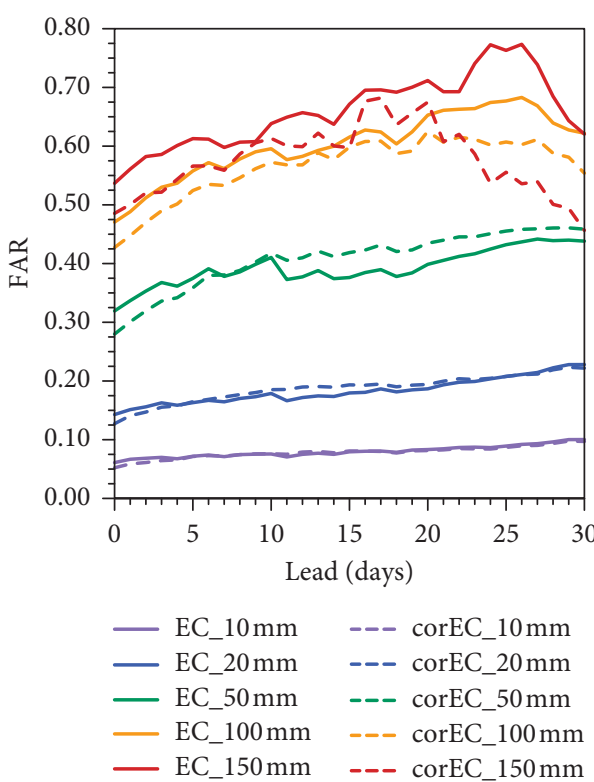

(a)
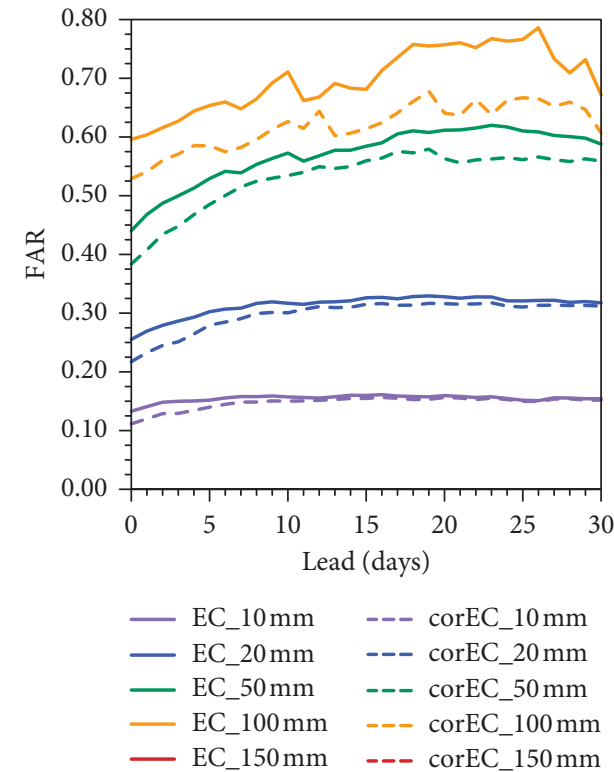

(b)

Figure 11: Continued. 

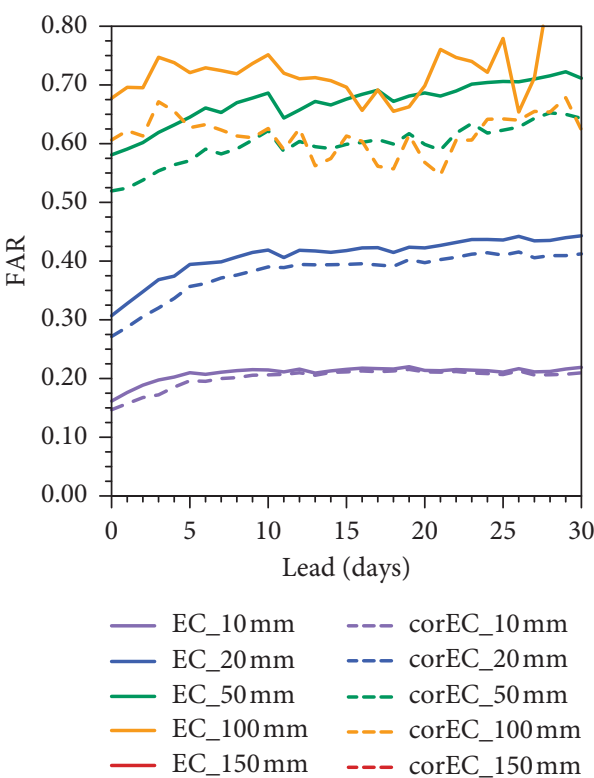

(c)
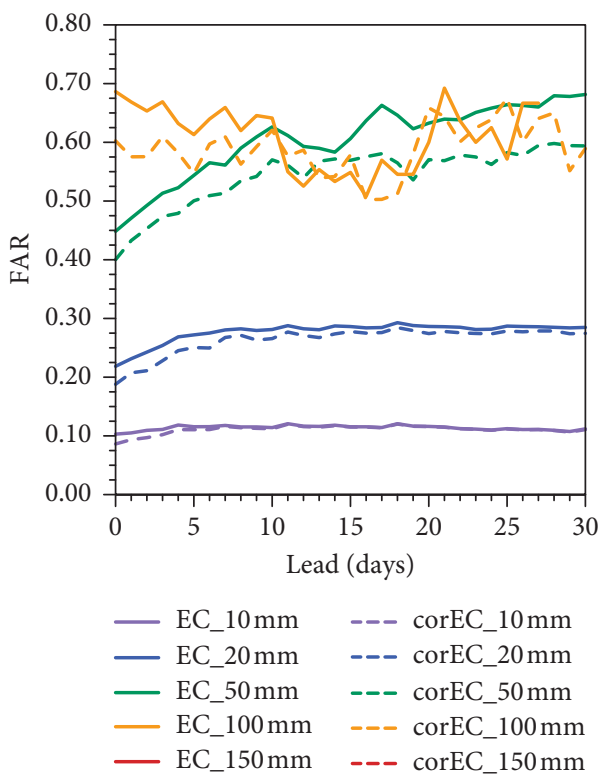

(e)

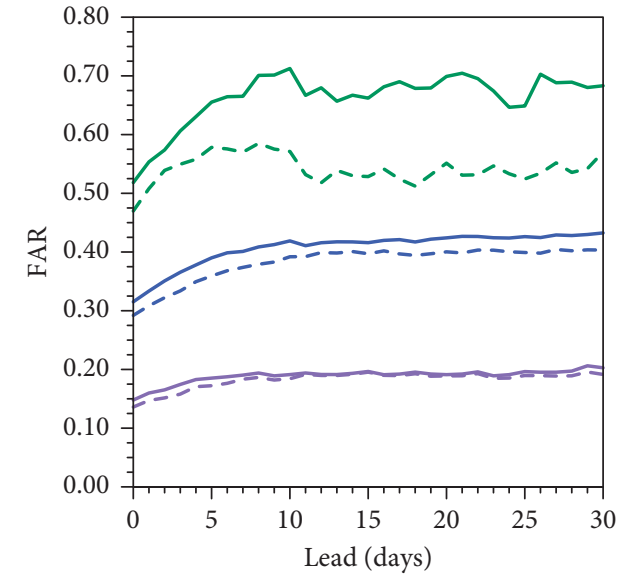

$\begin{array}{ll}\text { - EC_10 } \mathrm{mm} & --- \text { corEC_10 } \mathrm{mm} \\ - \text { EC_20 } \mathrm{mm} & --- \text { corEC_20 } \mathrm{mm} \\ - \text { EC_50 } \mathrm{mm} & --- \text { corEC_50 } \mathrm{mm} \\ - \text { EC_100 } \mathrm{mm} & --- \text { corEC_100 mm } \\ \text { - EC_150 } \mathrm{mm} & --- \text { corEC_150 } \mathrm{mm}\end{array}$

(d)

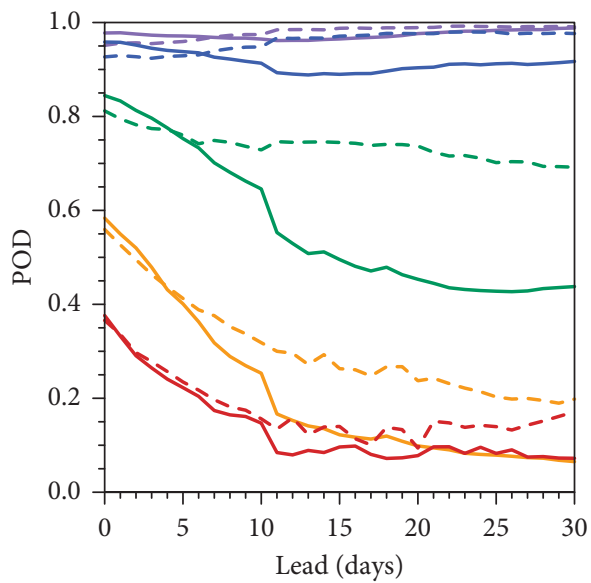

$\begin{array}{ll}\text { - EC_10 } \mathrm{mm} & --- \text { corEC_10 } \mathrm{mm} \\ - \text { EC_20 mm } & --- \text { corEC_20 } \mathrm{mm} \\ - \text { EC_50 mm } & --- \text { corEC_50 } \mathrm{mm} \\ \text { - EC_100 } \mathrm{mm} & --- \text { corEC_100 } \mathrm{mm} \\ \text { - EC_150 mm } & --- \text { corEC_150 } \mathrm{mm}\end{array}$

(f)

Figure 11: Continued. 

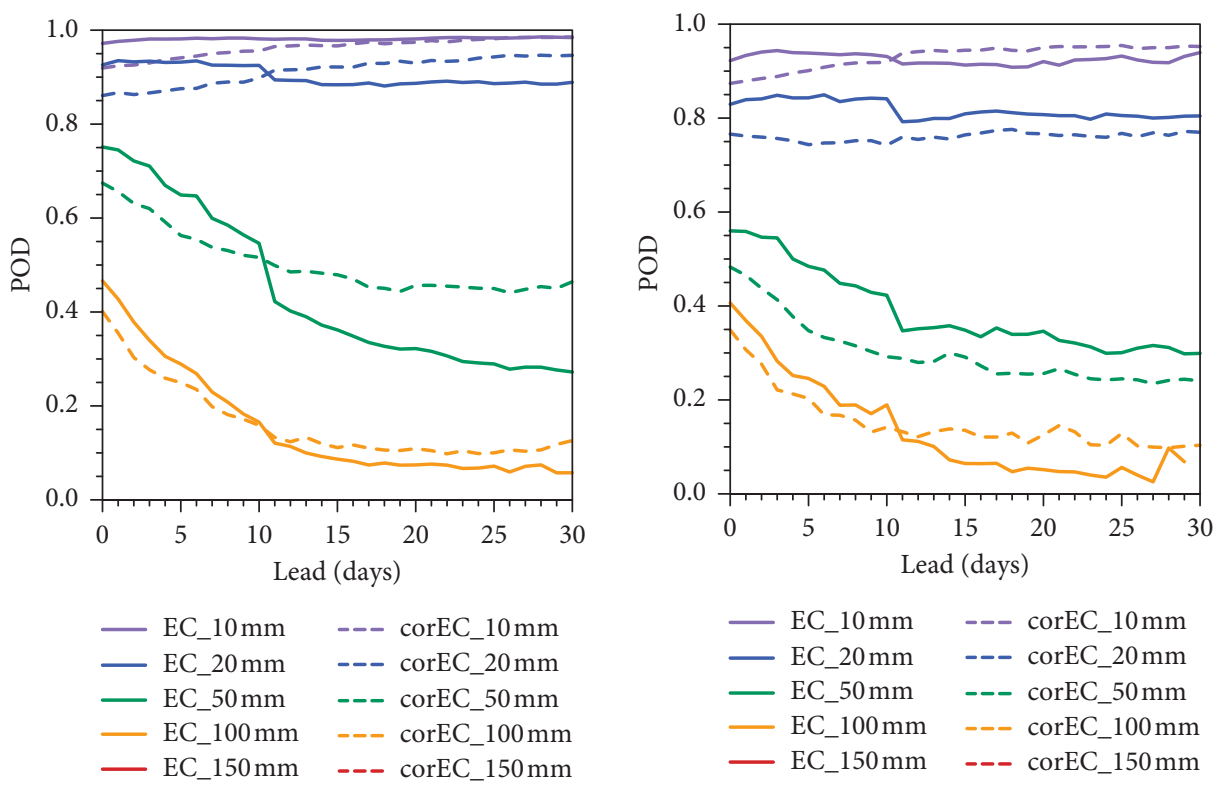

(g)

(h)
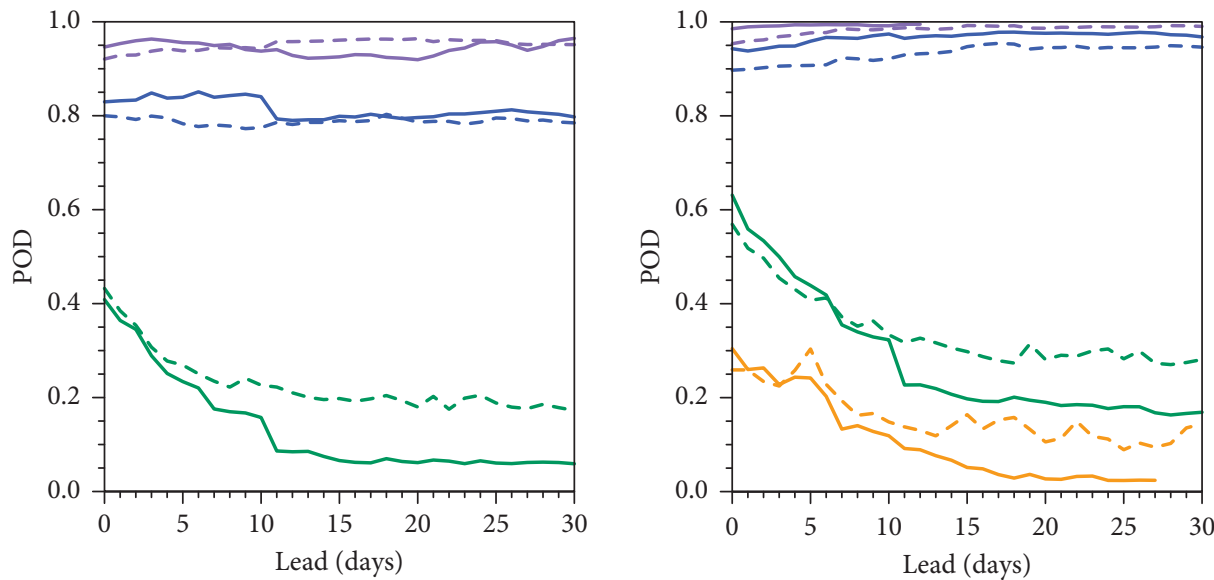

$\begin{array}{ll}\text { EC_10 mm } & --- \text { corEC_10 mm } \\ \text { - EC_20 mm } & --- \text { corEC_20 mm } \\ \text { - EC_50 mm } & --- \text { corEC_50 mm } \\ \text { - EC_100 mm } & --- \text { corEC_100 mm } \\ \text { - EC_150 mm } & --- \text { corEC_150 mm }\end{array}$

$\begin{array}{ll}\text { - EC_10 mm } & --- \text { corEC_10 } \mathrm{mm} \\ - \text { EC_20 mm } & --- \text { corEC_20 } \mathrm{mm} \\ \text { - EC_50 mm } & --- \text { corEC_50 } \mathrm{mm} \\ \text { - EC_100 } \mathrm{mm} & --- \text { corEC_100 } \mathrm{mm} \\ \text { - EC_150 } \mathrm{mm} & --- \text { corEC_150 } \mathrm{mm}\end{array}$

(i)

(j)

Figure 11: Continued. 

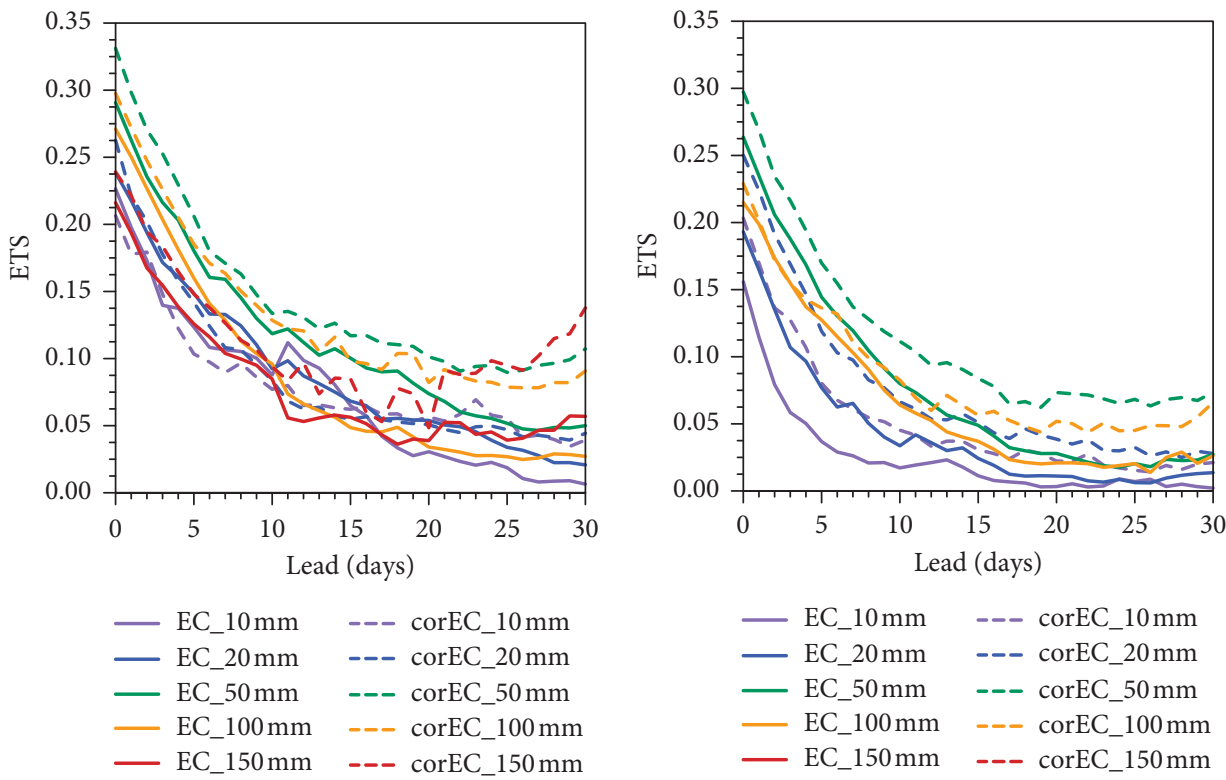

(k)
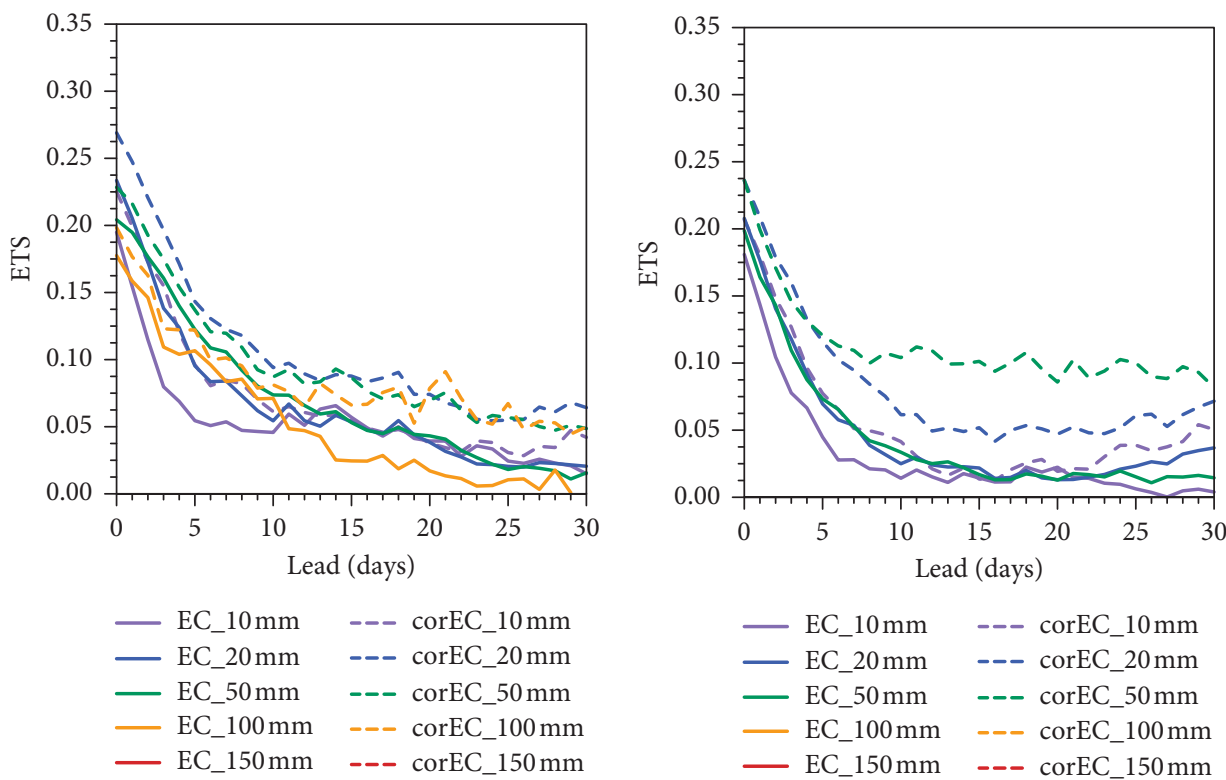

(m)

(n)

Figure 11: Continued. 


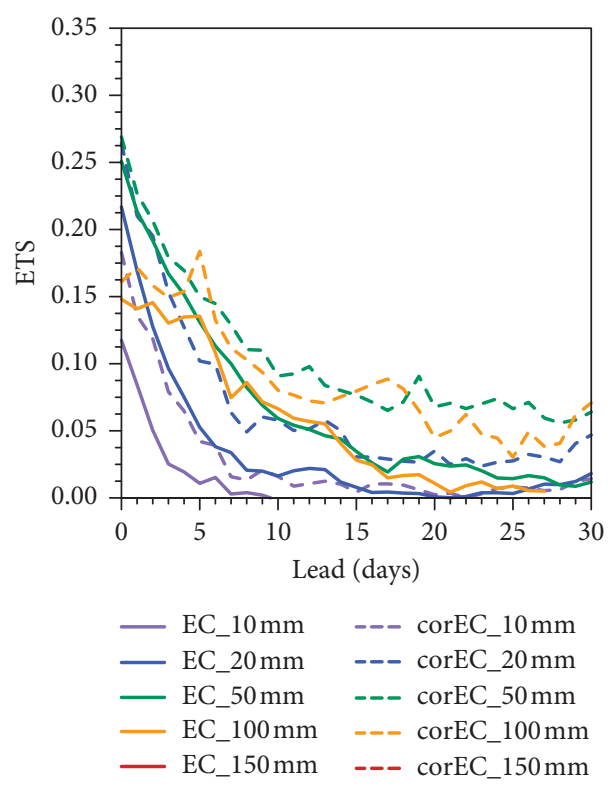

(o)

Figure 11: The FAR, POD, and ETS in (a, f, and k). Reg1; (b, g, and l). Reg2; (c, h, and m). Reg3; (d, i, and n). Reg4; (e, j, and o). Reg5 of eastern China from error-uncorrected and error-corrected ECMWF S2S hindcast experiment for rainy events exceeding 10, 20, 50, 100, and 150 mm over ten days at the lead times of 0-30 days, and the period is 1995-2014. Purple, blue, green, orange, and red lines represent the results of erroruncorrected ECMWF hindcast for rainy events exceeding 10,20, 50, 100, and $150 \mathrm{~mm}$ over ten days. Purple, blue, green, orange, and red dashed lines indicate the results of error-corrected ECMWF hindcast for rainy events exceeding 10, 20, 50, 100, and $150 \mathrm{~mm}$ over ten days.

that the best forecast skill corresponds to Southeast China (Reg1). Comparing the ETS scores of the uncorrected and corrected hindcasts, the scores of the corrected hindcast are obviously higher than those of the uncorrected hindcast, and the forecast skill of the ECMWF hindcast is enhanced after the error correction. Combining the three scores of the FAR, POD, and ETS reveals that the ECMWF hindcast tends to have a higher forecast skill for precipitation rates of approximately 20 50 $\mathrm{mm}$ over eastern China.

\section{Conclusions}

In this study, the ECMWF model hindcast, which participates in the S2S prediction project, is assessed. The focus is placed on the performance of the model in forecasting summer subseasonal precipitation at lead times of 0-30 days over the period of 1995-2014 in eastern China, and the hindcast error is corrected to improve the capability of the ECMWF hindcast.

The performance of the ECMWF hindcast is relatively superior among the JMA, CMA, and ECMWF S2S models. The ECMWF hindcast shows a higher temporal correlation at lead times of $0-5$ days, and its precipitation forecasting quality decreases gradually with an increasing lead time. The agreement between the ECMWF hindcast and observed summer accumulated ten-day precipitation with regard to the temporal variation of precipitation reveals that the performance of the ECMWF hindcast is regionally powerful. The highest temporal correlation is always reflected in Southeast China (Reg1), and the useful forecast skill of the hindcast is approximately 15 days in some areas of this subregion. In addition, the performance of the ECMWF hindcast has strong interannual differences among the five subregions of eastern China. The TCC values indicate that although the performance of the ECMWF model is relatively superior among the three S2S models, the forecast quality has considerable deficiencies and should be further enhanced.

This paper adopts the correlation between the monthly RMSE of precipitation and the two preceding months of SST to correct the forecast error and improve the performance of the ECMWF model. After correcting the forecast error, the agreement in the temporal variation between the ECMWF hindcast and the observed summer accumulated ten-day precipitation is enhanced slightly at lead times of 0-5 days and significantly at lead times of 10-30. Besides, the forecast skill of the ECMWF hindcast is still the best in Southeast China (Reg1), and the useful skill is increased to approximately 30 days in some areas of this subregion. The spatial distribution of the RMSE reveals that regardless of whether the forecast error is corrected, the RMSE values gradually increase with increasing lead time, especially in Southeast China (Reg1), and the RMSE values decrease from southeast to northwest in eastern China. After correcting the forecast error, the forecast error decreases significantly, which means that the performance of the ECMWF hindcast is improved. The agreement between the hindcasts and observations regarding the temporal variation and quantity of precipitation is improved significantly after correcting the forecast error, which means that adopting the preceding 
SST to correct the precipitation error can effectively improve the performance of the ECMWF hindcast. Comparing the interannual variations of the TCC between the hindcasts and observed precipitation for the uncorrected and corrected models, it is not difficult to find that the performance of the ECMWF hindcast has a strong interannual difference regardless of whether the forecast error is corrected. The performance of the error-corrected ECMWF hindcast is improved among the five subregions in most years at lead times of 0-30 days; the useful forecast skill can increase to as high as 30 days in some years. After correcting the forecast error, the useful skill of the ECMWF hindcast increases by 1-2 days in every subregion but increases by 15 days in some areas of Southeast China (Reg1), and the TCC values increase more distinctly (approximately 0.1 ) as the lead time increases. In addition, the forecast error exhibits the greatest decrease in North China (Reg3), and a significantly lower forecast error appears in the eastern part of Northeast China (Reg5) after the correction. Additionally, the performance of the ECMWF hindcast is pronouncedly improved in depicting the agreement in the spatial variation between the hindcasts and observed precipitation after correcting the forecast error. The SCC increases the most in Southeast China (Reg1) and the Huaihe River (Reg2), while the SCC is higher in North China (Reg3) than in the other subregions. The FAR, POD, and ETS scores indicate that the hindcast has a preferable forecast skill for accumulated ten-day precipitation rates of approximately $20 \sim 50 \mathrm{~mm}$. After an error correction, most FAR scores are reduced, and most POD and ETS scores are increased in eastern China.

In summary, adopting the correlation between the monthly RMSE of precipitation and the two preceding months of SST corrects the ECMWF hindcast error; consequently, the precipitation forecast skill of the ECMWF S2S hindcast is improved significantly, and the forecast performance is the best in Southeast China (Reg1). Based on the analysis of the ECMWF hindcast performance in this study, we plan to determine the reasons why the capability of the ECMWF hindcasts exhibits strong interannual differences and then establish a scheme to eliminate these interannual differences. This will be an additional approach to improve the precipitation forecast performance of ECMWF hindcast experiments.

\section{Data Availability}

The S2S database is available online at http://apps.ecmwf.int/ datasets/data/s2s/ and http://s2s.cma.cn/. The Chinese daily precipitation data are provided by the National Meteorological Information Center of the China Meteorological Administration from http://data.cma.cn/. The SST data are acquired by Met Office Hadley Center from https://www. metoffice.gov.uk/hadobs/hadisst/.

\section{Conflicts of Interest}

The authors declare that there are no conflicts of interest regarding the publication of this paper.

\section{Acknowledgments}

This work was jointly supported by the National Key Research and Development Program of China (nos. 2018YFC1505802 and 2016YFA0602104) and China 973 Project (2015CB453201).

\section{References}

[1] E. N. Lorenz, "A study of the predictability of a 28-variable atmospheric model," Tellus, vol. 17, no. 3, pp. 321-333, 1965.

[2] E. N. Lorenz, "Atmospheric predictability as revealed by naturally occurring analogues," Journal of the Atmospheric Sciences, vol. 26, no. 4, pp. 636-646, 1969.

[3] E. Kalnay, Atmospheric Modeling, Data Assimilation and Predictability, Cambridge University Press, New York, USA, 2003.

[4] J. G. Charney and J. Shukla, "Predictability of monsoons," in Monsoon Dynamics, J. Lighthill and R. P. Pearce, Eds., Cambridge University Press, Cambridge, UK, pp. 99-109, 1981.

[5] J. Shukla, "Predictability in the midst of chaos: a scientific basis for climate forecasting," Science, vol. 282, no. 5389, pp. 728-731, 1998.

[6] T. N. Palmer and D. L. T. Anderson, "The prospects for seasonal forecasting-a review paper," Quarterly Journal of the Royal Meteorological Society, vol. 120, no. 518, pp. 755793, 1994.

[7] X. Liu, T. Wu, S. Yang et al., "MJO prediction using the subseasonal to seasonal forecast model of Beijing climate center," Climate Dynamic, vol. 48, no. 9-10, pp. 3283-3307, 2017.

[8] F. Vitart, C. Ardilouze, A. Bonet et al., "The sub-seasonal to seasonal prediction (S2S) project database," Bulletin of the American Meteorological Society, vol. 98, no. 1, pp. 163-173, 2017.

[9] F. Vitart, A. W. Robertson, and D. L. T. Anderson, "Subseasonal to seasonal prediction project: bridging the gap between weather and climate," WMO Bulletin, vol. 61, no. 2, pp. 23-28, 2012.

[10] P. Liang and H. Lin, "Sub-seasonal prediction over east Asia during boreal summer using the ECCC monthly forecasting system," Climate Dynamics, vol. 50, no. 3-4, pp. 1007-1022, 2018.

[11] D. E. Waliser, K. M. Lau, W. Stern, and C. Jones, "Potential predictability of the Madden-Julian oscillation," Bulletin of the American Meteorological Society, vol. 84, no. 1, pp. 33-50, 2003.

[12] J. M. Neena, J. Y. Lee, D. Waliser, B. Wang, and X. Jiang, "Predictability of the Madden-Julian oscillation in the intraseasonal variability hindcast experiment (ISVHE)," Journal of Climate, vol. 27, no. 12, pp. 4531-4543, 2014.

[13] S. Li and A. W. Robertson, "Evaluation of submonthly precipitation forecast skill from global ensemble prediction systems," Monthly Weather Review, vol. 143, no. 7, pp. 2871-2889, 2015.

[14] R. D. Koster, S. P. P. Mahanama, T. J. Yamada et al., "The contribution of land surface initialization to subseasonal forecast skill," Geophysical Research Letters, vol. 37, no. 2, pp. 489-496, 2010.

[15] S. Kumar, P. A. Dirmeyer, D. M. Lawrence et al., "Effects of realistic land surface initializations on subseasonal to seasonal soil moisture and temperature predictability in North America and in changing climate simulated by CCSM4," 
Journal of Geophysical Research: Atmospheres, vol. 119, no. 23, pp. 250-313, 2014.

[16] J.-H. Jeong, H. W. Linderholm, S.-H. Woo et al., "Impacts of snow initialization on subseasonal forecasts of surface air temperature for the cold season," Journal of Climate, vol. 26, no. 6, pp. 1956-1972, 2013.

[17] M. M. Holland, D. A. Bailey, and S. Vavrus, "Inherent sea ice predictability in the rapidly changing Arctic environment of the community climate system model version 3," Climate Dynamics, vol. 36, no. 7-8, pp. 1239-1253, 2011.

[18] M. P. Baldwin, "Stratospheric memory and skill of extendedrange weather forecasts," Science, vol. 301, no. 5633, pp. 636-640, 2003.

[19] A. A. Scaife and J. R. Knight, "“Ensemble simulations of the cold European winter of 2005-2006," Quarterly Journal of the Royal Meteorological Society, vol. 134, no. 636, pp. 1647-1659, 2010.

[20] F. Vitart, Sub-Seasonal to Seasonal Prediction: Linking Weather and Climate, WMO, Geneva, Switzerland, 2015.

[21] J. Black, N. C. Johnson, S. Baxter, S. B. Feldstein, D. S. Harnos, and M. L. L'Heureux, "The predictors and forecast skill of northern hemisphere teleconnection patterns for lead times of 3-4 weeks," Monthly Weather Review, vol. 145, no. 7, pp. 2855-2877, 2017.

[22] H. Zhu, M. C. Wheeler, A. H. Sobel, and D. Hudson, "Seamless precipitation prediction skill in the tropics and extratropics from a global model," Monthly Weather Review, vol. 142, no. 4, pp. 1556-1569, 2014.

[23] M. C. Wheeler, H. Zhu, A. H. Sobel, D. Hudson, and F. Vitart, "Seamless precipitation prediction skill comparison between two global models," Quarterly Journal of the Royal Meteorological Society, vol. 143, no. 702, pp. 374-383, 2017.

[24] H. Lin, G. Brunet, and J. Derome, "Forecast skill of the madden-julian oscillation in two Canadian atmospheric models," Monthly Weather Review, vol. 136, no. 11, pp. 4130-4149, 2008.

[25] H. A. Rashid, H. H. Hendon, M. C. Wheeler et al., "Prediction of the Madden-Julian oscillation with the POAMA dynamical prediction system," Climate Dynamics, vol. 36, no. 3-4, pp. 649-661, 2011.

[26] H.-M. Kim, P. J. Webster, V. E. Toma, and D. Kim, "Predictability and prediction skill of the MJO in two operational forecasting systems," Journal of Climate, vol. 27, no. 14, pp. 5364-5378, 2014.

[27] B. Xiang, M. Zhao, X. Jiang et al., "The 3-4-week MJO prediction skill in a GFDL coupled model," Journal of Climate, vol. 28, no. 13, pp. 5351-5364, 2015.

[28] P. C. Hsu, T. Li, L. You et al., "A spatial-temporal projection model for 10-30 day rainfall forecast in South China," Climate Dynamics, vol. 44, no. 5-6, pp. 1227-1244, 2015.

[29] Z. Zhu and T. Li, "The statistical extended-range (10-30 day) forecast of summer rainfall anomalies over the entire China," Climate Dynamics, vol. 48, no. 1-2, pp. 209-224, 2017.

[30] A. W. Robertson, A. Kumar, M. Peña, and F. Vitart, "Improving and promoting subseasonal to seasonal prediction," Bulletin of the American Meteorological Society, vol. 96, no. 3, pp. ES49-ES53, 2015.

[31] W. Jie, F. Vitart, T. Wu, and X. Liu, "Simulations of the Asian summer monsoon in the sub-seasonal to seasonal prediction project (S2S) database," Quarterly Journal of the Royal Meteorological Society, vol. 143, no. 706, pp. 2282-2295, 2017.

[32] F. M. De Andrade, C. A. S. Coelho, and I. F. A. Cavalcanti, "Global precipitation hindcast quality assessment of the subseasonal to seasonal (S2S) prediction project models," Climate Dynamics, vol. 9, pp. 1-25, 2019.

[33] V. Nicolas, A. W. Robertson, M. K. Tippett et al., "Subseasonal predictability of boreal summer monsoon rainfall from ensemble forecasts," Frontiers in Environmental Science, vol. 5, no. 67, 2017.

[34] Y. Zhou, B. Yang, H. Chen, Y. Zhang, A. Huang, and M. La, "Effects of the Madden-Julian oscillation on $2 \mathrm{~m}$ air temperature prediction over China during boreal winter in the S2S database," Climate Dynamics, vol. 52, no. 11, pp. 6671-6689, 2019.

[35] F. B. Fu, L. Q. Xue, and L. Ren, "Precursor signals and prediction of summer drought and flood in the Huaihe river basin," Journal of Water Resources \& Water Engineering, vol. 30, no. 1, pp. 13-20, 2019, in Chinese.

[36] X. L. Jia, "Anomalies of the northeast China floods season precipitation and the relations with SSTA," M.S. thesis, Nanjing Institute of Meteorology, Nanjing, China, 2003, in Chinese.

[37] J. Gao and H. Gao, "Relationship between summer precipitation over Northeastern China and sea surface temperature in the Southeastern Pacific and the possible underlying mechanisms," Chinese Journal of Atmospheric Sciences, vol. 39, no. 5, pp. 967-977, 2015, in Chinese.

[38] A. J. Deng, S. Y. Tao, and L. T. Chen, "Spatial and temporal distribution of SST in the Indian Ocean and its relationship with precipitation in flood season over China," Chinese Journal of Atmospheric Sciences, vol. 4, pp. 393-399, 1989, in Chinese.

[39] Y. Li, B. Wu, Q. Yang, and S. Huang, "Different relationships between spring SST in the Indian and Pacific Oceans and summer precipitation in China," Acta Meteorologica Sinica, vol. 27, no. 4, pp. 509-520, 2013.

[40] L. Wang and R. H. Zhang, "Diagnostic researches and forecasting experiments of the various regional sea surface temperature anomaly on summer precipitation in China," Chinese Journal of Atmospheric Sciences, vol. 6, pp. 1147-1159, 2006, in Chinese.

[41] N. A. Rayner, "Global analyses of sea surface temperature, sea ice, and night marine air temperature since the late nineteenth century," Journal of Geophysical Research Atmospheres, vol. 108, p. 4407, 2003.

[42] F. Su, H. Gao, G. J. Huffman, and D. P. Lettenmaier, "Potential utility of the real-time TMPA-RT precipitation estimates in streamflow prediction," Journal of Hydrometeorology, vol. 12, no. 3, pp. 444-455, 2011.

[43] H. Chen and Z. Lin, "A correction method suitable for dynamical seasonal prediction," Advances in Atmospheric Sciences, vol. 23, no. 3, pp. 425-430, 2006.

[44] E. Habib, A. Henschke, and R. F. Adler, "Evaluation of TMPA satellite-based research and real-time rainfall estimates during six tropical-related heavy rainfall events over Louisiana, USA," Atmospheric Research, vol. 94, no. 3, pp. 373-388, 2009.

[45] A. Aghakouchak, A. Mehran, H. Norouzi et al., "Systematic and random error components in satellite precipitation data sets," Geophysical Research Letters, vol. 39, no. 9, Article ID L09406, 2012. 